\title{
Activation of IGF-1 and Insulin Signaling Pathways Ameliorate Mitochondrial Function and Energy Metabolism in Huntington's Disease Human Lymphoblasts
}

\author{
Luana Naia • I. Luísa Ferreira • Teresa Cunha-Oliveira • Ana I. Duarte • Márcio Ribeiro • \\ Tatiana R. Rosenstock • Mário N. Laço • Maria J. Ribeiro • Catarina R. Oliveira • \\ Frédéric Saudou • Sandrine Humbert • A. Cristina Rego
}

Received: 3 February 2014 / Accepted: 29 April 2014

(C) Springer Science+Business Media New York 2014

\begin{abstract}
Huntington's disease (HD) is an inherited neurodegenerative disease caused by a polyglutamine repeat expansion in the huntingtin protein. Mitochondrial dysfunction associated with energy failure plays an important role in this untreated pathology. In the present work, we used lymphoblasts obtained from HD patients or unaffected parentally related individuals to study the protective role of insulin-like growth factor 1 (IGF-1) versus insulin (at low $\mathrm{nM}$ ) on signaling and metabolic and mitochondrial functions. Deregulation of intracellular signaling pathways linked to activation of insulin and IGF-1 receptors (IR,IGF-1R), Akt, and ERK was largely restored by IGF-1 and, at a less extent, by insulin in HD human lymphoblasts. Importantly, both neurotrophic
\end{abstract}

L. Naia and I. L. Ferreira contributed equally for this study.

L. Naia $\cdot$ I. L. Ferreira $\cdot$ T. Cunha-Oliveira $\cdot$ A. I. Duarte $\cdot$

M. Ribeiro • T. R. Rosenstock • M. N. Laço • M. J. Ribeiro •

C. R. Oliveira • A. C. Rego $(\square)$

CNC-Center for Neuroscience and Cell Biology, University of

Coimbra, Largo Marquês de Pombal, 3004-517 Coimbra, Portugal

e-mail: a.cristina.rego@gmail.com

A. C. Rego

e-mail: arego@fmed.uc.pt

A. C. Rego

e-mail: acrego@cnc.uc.pt

L. Naia $\cdot$ M. N. Laço $\cdot$ C. R. Oliveira • A. C. Rego

Faculty of Medicine, University of Coimbra, Coimbra, Portugal

I. L. Ferreira • T. Cunha-Oliveira • A. I. Duarte - T. R. Rosenstock •

M. N. Laço • C. R. Oliveira • A. C. Rego

Institute for Interdisciplinary Research, University of Coimbra

(IIIUC), Polo II, Coimbra, Portugal

F. Saudou $\cdot$ S. Humbert

Institut Curie, Orsay 91405, France factors stimulated huntingtin phosphorylation at Ser421 in HD cells. IGF-1 and insulin also rescued energy levels in HD peripheral cells, as evaluated by increased ATP and phosphocreatine, and decreased lactate levels. Moreover, IGF-1 effectively ameliorated $\mathrm{O}_{2}$ consumption and mitochondrial membrane potential $\left(\Delta \psi_{\mathrm{m}}\right)$ in HD lymphoblasts, which occurred concomitantly with increased levels of cytochrome c. Indeed, constitutive phosphorylation of huntingtin was able to restore the $\Delta \psi_{\mathrm{m}}$ in lymphoblasts expressing an abnormal expansion of polyglutamines. HD lymphoblasts further exhibited increased intracellular $\mathrm{Ca}^{2+}$ levels before and after exposure to hydrogen peroxide $\left(\mathrm{H}_{2} \mathrm{O}_{2}\right)$, and decreased mitochondrial $\mathrm{Ca}^{2+}$ accumulation, being the later recovered by IGF-1 and insulin in $\mathrm{HD}$ lymphoblasts pre-exposed to $\mathrm{H}_{2} \mathrm{O}_{2}$. In summary, the data support an important role for IR/IGF-1R mediated activation of signaling pathways and improved mitochondrial and metabolic function in HD human lymphoblasts.

Keywords Huntington's disease · Insulin · IGF-1 · Intracellular signaling $\cdot$ Mitochondria $\cdot$ Energy metabolism

\section{Introduction}

Huntington's disease (HD) is an autosomal progressive neurodegenerative disorder, characterized by an age-dependent loss in motor coordination, cognitive impairment, psychiatric disturbances and dementia, affecting about 10 in 10,000 individuals $[1,2]$. HD neuropathology involves the selective death of striatal medium-sized spiny neurons due to an expansion of CAG repeats, encoding for a polyglutamine stretch at the Nterminus of the huntingtin $(\mathrm{Htt})$ protein, which results in the formation of intranuclear aggregates [3, 4]. The current 
hypothesis suggests that the disease arises from the combined effects of a gain of function in the mutated form of $\mathrm{Htt}(\mathrm{mHtt})$, along with a loss of function of wild-type Htt [5]. Despite these well-defined molecular alterations, many factors have been implicated in HD, including excitotoxicity, oxidative stress, alterations in $\mathrm{Ca}^{2+}$ handling, as well as a deregulation in transcription and intracellular signaling pathways $[1,6]$. Importantly, impaired energy metabolism and mitochondrial function also play a central role in HD pathogenesis [7, 8]. Nevertheless, currently there is no neuroprotective treatment to prevent HD onset, disease progression, or patients' death.

Although HD affects mostly the central nervous system, growing evidence describes changes in peripheral tissues, such as lymphocytes [9], erythrocytes [10], fibroblasts [11], or platelets [12]. Abnormalities in weight loss and glucose homeostasis are also common clinical features among HD patients [13]. Furthermore, several studies in HD patients corroborated metabolic and mitochondrial dysfunction, showing (i) decreased mitochondrial complexes II, III, and IV activities in post-mortem brain samples and platelets $[12,14]$ and increased lactate levels in striatum and cortex [15]; (ii) reduced phosphocreatine/inorganic phosphate ratio in skeletal muscle [16]; and (iii) abnormal mitochondrial membrane potential in lymphoblasts $[9,11]$, and mitochondrial fragmentation in fibroblasts from HD patients [17]. In addition, previous studies performed in HD human cybrids (derived from HD human platelets) demonstrated an increase in mitochondrial Bim and Bak levels, and a slight release of cytochrome c, suggesting increased susceptibility to mitochondrialdependent apoptosis [18]. More recent data evidenced mitochondrial dysfunction through decreased pyruvate dehydrogenase protein levels and activity, with consequent boosting of glycolysis in HD human cybrids [19], supporting bioenergetic disturbances in these cells.

Several studies have identified compounds that might be of therapeutic interest in HD. Neurotrophic factors such as insulin or insulin-like growth factor 1 (IGF-1) have been considered as potential therapeutic agents in neurodegenerative disorders $[20,21]$. Previously, we demonstrated that insulin prevented the increase in both apoptotic and necrotic neuronal death associated with oxidative damage [22]. Moreover, insulin stimulated neuronal glucose uptake and subsequent metabolism into pyruvate, restoring intracellular ATP levels [23]. Besides regulating neuronal metabolism, insulin was shown to be neuroprotective against oxidative stress mediated by insulin receptor (IR)- and/or IGF-1 receptor (IGF-1R)-induced activation of phosphoinositide 3-kinase (PI3K)/Akt, inhibition of glycogen synthase kinase-3 $\beta$ (GSK-3 $\beta$ ) [24] and forkhead box O1 (FoxO1) signaling pathways [25]. Other studies showed the beneficial effect of IGF-1, which regulates the size of neuronal populations during brain development [26, 27]. Moreover, the increase in IGF-1 and IGF-1R expression was associated to increased Akt (or protein kinase B) and extracellular signal regulated kinase (ERK)1/2 phosphorylation [28]. Indeed, IGF-1 appears to be neuroprotective in the brain of ischemic rats, since it decreased neuronal apoptosis and improved motor function [29]. Furthermore, IGF-1 prevented neuronal death and protein aggregation induced by expression of $\mathrm{mHtt}$; importantly, phosphorylation of $\mathrm{Htt}$ at Ser421 by Akt was shown to be essential for mediating this neuroprotective effect [21]. Recently, IGF-1 intranasal administration enhanced brain cortical IGF-1 levels and ameliorated Akt and Htt phosphorylation at Ser421, energy metabolic features, and motor function in YAC128 mice [30]. In addition, Pouladi et al. [31] described reduced IGF-1 expression in caudate and skin-derived fibroblasts from HD patients; moreover, proteomics profiling of plasma demonstrated that levels of the IGFALS, a component of the IGF-1 ternary binding complex, are reduced in HD patients [32]. Conversely, Saleh et al. [33, 34] detected elevated plasma levels of IGF-1 associated with the severity of cognitive impairment in HD patients. Moreover, another study showed an increase in neuronal oxidative stress and mitochondrial dysfunction in transgenic R6/2 mice overexpressing insulin receptor substrate 2 (Irs2), a cytoplasmic molecule that mediates the effects of insulin and IGF-1 [35].

In light of these conflicting results, in this study, we explored how IGF-1 versus insulin (at low nM), acting through activation of IR,IGF-1R-mediated intracellular signaling, modulate HD-related mitochondrial and metabolic dysfunction, using human HD and family-related control lymphoblasts. This peripheral cell model derived from HD patients was previously shown to share several abnormalities related to $\mathrm{mHtt}$, such as mitochondrial dysfunction, increased apoptosis, and transcriptional abnormalities [13]. Herein, we demonstrate reduced Akt and ERK activation and Htt phosphorylation, associated with reduced energy metabolism and mitochondrial dysfunction in HD human lymphoblasts, which are efficiently prevented by IGF-1 and, to a less extent, by insulin.

\section{Material and Methods}

\section{Materials}

Fetal bovine serum (FBS) and penicillin/streptomycin were from Gibco (Paisley, Scotland, UK). Insulin from porcine pancreas, IGF-1, glucose-6-phosphate, NADP, ADP, G6PDH, hexokinase, creatine kinase, protease inhibitor cocktail, oligomycin, CCCP, RPMI-1640 medium, and antitubulin were from Sigma Aldrich (St. Louis, MO, USA). enhanced chemifluorescence reagent, anti-rabbit IgG (from goat), and anti-mouse IgG+IgM (from goat) were from GE Healthcare (Little Chalfort, UK). Hoechst 33342, Alexa Fluor 488 goat anti-rabbit IgG, anti-complex (Cx) I ( $20 \mathrm{kDa})$ subunit, and anti-Cx IV (57 kDa) subunit were obtained from 
Invitrogen (Carlsbad, CA, USA). Fura-2/AM, tetramethyl rhodamine methyl ester $\left(\mathrm{TMRM}^{+}\right)$, MitoTracker Red CMXRos, anti-Cx I (30 kDa), and anti-Cx II (70 kDa) subunits were obtained from Molecular Probes/Invitrogen (Eugene, OR, USA). Lactate and pyruvate kits and anti-Tfam were from Abcam (Cambridge, UK). Amaxa cell line nucleofector Kit V was from Lonza (Basel, Switzerland). Bio-Rad Protein Assay was from Bio-Rad (Hemel Hempstead, UK). Anti-P-Akt (Ser473), anti-Akt, anti-p44/42 ERK (Thr202/Thr204), anti-p44/42 ERK, anti-IR/IGF-1R, anti-PFoxo1 (Ser256), anti-Foxo1, anti-P-mTor (Ser2448), antimTor, anti-Bax, anti-p65, and anti-p53 were from Cell Signaling (Beverly, MA, USA). Polyvinylidene fluoride (PVDF) membrane and anti-P-IR/IGF-1R (Y1158/Y1162/Y1163) were from Millipore (Billerica, MA, USA). Anti-P-GSK-3 $\beta$ (Tyr216), anti-GSK-3 $\beta$, anti-prohibitin, anti-TOM20, antiTOM40 and anti-apoptosis-inducing factor (AIF) were from Santa Cruz Biotechnology (Santa Cruz, CA, USA). AntiHsp60 and anti-Htt (MAB1266) were obtained from Chemicon (Hampshire, UK). Anti-cytochrome c was from BD Biosciences Pharmingen (San Diego, CA, USA). Anti$\mathrm{P}(\mathrm{Ser} 421) \mathrm{Htt}$ was produced at Institute Curie (Orsay, France). Dako fluorescent mounting medium was from Palex Medical (Barcelona, Spain).

\section{Cell Lines Culture and Treatment}

Human lymphoblastoid cell lines, obtained from Coriell Institute for Medical Research (USA), were derived from HDaffected patients containing heterozygous expansion mutation, four males $(43 / 15,45 / 15,42 / 18$, and 49/17) and one female (47/18), or from unaffected voluntary control siblings, three males and one female, defined in this work as control (CTR) lymphoblasts. Lymphoblasts were maintained at a density of 400,000-600,000 cells $/ \mathrm{mL}$ and cultured in RPMI1640 medium supplemented with $15 \%(v / v)$ non-inactivated FBS, $2 \mathrm{mM}$ L-glutamine and $50 \mu \mathrm{g} / \mathrm{mL}$ streptomycin plus $100 \mathrm{IU} / \mathrm{mL}$ penicillin in T25 or T75 flasks, in upright position, using an incubator chamber containing $5 \% \mathrm{CO}_{2}, 95 \%$ air, and $100 \%$ humidity, at $37^{\circ} \mathrm{C}$. In these conditions, lymphoblastoid cell lines grow in suspension with cells clumped in loose aggregates. When used, these aggregates were dissociated by gently agitating the culture or by gentle trituration with a pipette. In 3-4 days, the cultures were either re-fed with fresh medium or split according to the rate of cell growth or the required number of cells needed for the experiments. For each experiment, HD or CTR cells were plated at 500,000 cells $/ \mathrm{mL}$ in fresh RPMI medium and incubated for $24 \mathrm{~h}$, in the absence (basal) or presence of $0.1 \mathrm{nM}$ insulin or $0.1 \mathrm{nM}$ IGF-1. For immunocytochemistry studies, lymphoblasts were left to adhere on poly-D-lysine glass coverslips $\left(50,000\right.$ cells $\left./ \mathrm{cm}^{2}\right)$ for $1 \mathrm{~h}$ and then processed as described in "Fluorence Imaging."
Constructs and Transfection

The wild-type and polyQ-Htt constructs, 480-17Q, 480-68Q, 480-68-S421D, and 480-68-S421A, have been previously described [21]. CTR lymphoblasts were transiently transfected with $2 \mu \mathrm{g}$ plasmid DNA using Amaxa cell line nucleofector kit V $48 \mathrm{~h}$ before the experiment. Electroporation was carried out using the Lonza Nucleofector $2 b$ device (Lonza, Switzerland) adjusted for E-032 program. Four hours after electroporation, RPMI medium was replaced by fresh medium to reduce the toxicity associated to the transfection medium.

Preparation of Total, Mitochondrial, and Cytosolic-Enriched Fractions and Western Blotting

HD and CTR lymphoblasts non-treated or treated with insulin or IGF-1 were centrifuged at $145 \times \mathrm{g}$, for $5 \mathrm{~min}$, and washed with phosphate-buffered saline (PBS) solution containing (in $\mathrm{mM}$ ): $137 \mathrm{NaCl}, 2.7 \mathrm{KCl}, 1.4 \mathrm{~K}_{2} \mathrm{HPO}_{4}$, and $4.3 \mathrm{KH}_{2} \mathrm{PO}_{4}$, at pH 7.4.

Total Fractions Extracts were prepared in ice-cold lysis buffer (in mM: 20 Tris, $100 \mathrm{NaCl}, 2$ EDTA, 2 EGTA, $50 \mathrm{NaF}, 1$ $\mathrm{Na}_{3} \mathrm{VO}_{4}, 1 \%$ Triton; $\mathrm{pH}$ 7.4) supplemented with $1 \mathrm{mM} \mathrm{1,4-}$ dithiothreitol (DTT), $100 \mu \mathrm{M}$ phenylmethylsulfonyl fluoride (PMSF), $100 \mathrm{nM}$ okadaic acid and $1 \mu \mathrm{g} / \mathrm{mL}$ protease inhibitor cocktail (chymostatin, pepstatin A, leupeptin, and antipain). The homogenates (total fractions) were then frozen/thawed three times in liquid nitrogen and centrifuged at $20,800 \times g$ for $10 \min \left(4^{\circ} \mathrm{C}\right)$ in order to remove cell debris; the resulting supernatant was collected and stored at $80^{\circ} \mathrm{C}$ for later use.

Mitochondrial and Cytosolic-Enriched Fractions Cells were re-suspended in ice-cold sucrose buffer (in mM: 250 sucrose, $20 \mathrm{HEPES} / \mathrm{KOH}$ (pH 7.5), $100 \mathrm{KCl}, 1.5 \mathrm{MgCl}_{2}, 1$ EGTA, and 1 EDTA), supplemented with $1 \mathrm{mM}$ DTT, $100 \mu \mathrm{M}$ PMSF, $100 \mathrm{nM}$ okadaic acid, and $1 \mu \mathrm{g} / \mathrm{mL}$ protease inhibitor cocktail. Lysates, obtained after homogenization, were centrifuged at $560 \times g$ for $12 \mathrm{~min}\left(4^{\circ} \mathrm{C}\right)$ to pellet the nuclei and cell debris. The supernatant was further centrifuged at $12,000 \times g$ for $20 \mathrm{~min}\left(4^{\circ} \mathrm{C}\right)$ and the resulting pellet (mitochondrialenriched fraction) resuspended in supplemented sucrose buffer. TCA $(15 \%)$ was added to the supernatant, and precipitated proteins were centrifuged at $16,300 \times g$ for $10 \min \left(4{ }^{\circ} \mathrm{C}\right)$. The resulting pellet (cytosolic-enriched protein fraction) was resuspended in supplemented sucrose buffer and brought to pH 7 with $\mathrm{KOH}$ (as in [36]). Both fractions were stored at $80^{\circ} \mathrm{C}$ for later use.

For Western blotting, equivalent amounts of protein were subjected to sodium dodecyl sulfate polyacrylamide gel electrophoresis (SDS-PAGE) gel (10 or $12 \%$ ), transferred onto 
PVDF membranes, and incubated for phosphorylated proteins with anti-P-Akt (Ser473) (1:1,000), P-p44/42 ERK (Thr202/ Tyr204) (1:1,000), P(Tyr1158/Tyr1162/Tyr1163)-IR/IGF-1R (1:1,000), P-GSK-3 $\beta$ (Tyr216) (1:500), P-mTor (Ser2448) $(1: 1,000)$, P-Foxo1 (Ser256) (1:500), and P-Htt (Ser421) $(1: 200)$ antibodies. These phosphorylated proteins were further normalized using the following antibodies: Akt $(1: 1,000)$, p44/42 ERK (1:1,000), IR/IGF-1R (1:1,000), GSK-3 $\beta$ (1:500), mTor (1:1000), Foxo1 (1:750), and Htt(MAB2166) $(1: 250)$. For analysis of total proteins, membranes were incubated with TOM20 (1:200), TOM40 (1:500), prohibitin (1:2,000), Tfam (1:1,000), Bax (1:1,000), p65 (1:500), p53 $(1: 2,000)$, AIF $(1: 1,000)$, and cytochrome c (1:500) antibodies, overnight at $4^{\circ} \mathrm{C}$. These proteins were normalized using anti-tubulin $(1: 20,000)$ or Hsp60 $(1: 1,000)$ antibodies. Membranes were then incubated with anti-rabbit IgG and antimouse $\operatorname{IgG}+\operatorname{IgM}$ secondary antibodies $(1: 20,000)$, for $90 \mathrm{~min}$ at room temperature, and immunoreactive bands visualized using VersaDoc Imaging System (BioRad, Hercules, USA). Fluorescence signal was analyzed using the QuantityOne software, and the results were given as percentage of control.

Measurement of Intracellular Accumulation of Adenine Nucleotides, Phosphocreatine and Pyruvate Levels

HD or CTR lymphoblasts, treated or not with insulin or IGF1 , were washed with ice-cold PBS and centrifuged at $145 \times g$, for $5 \mathrm{~min}\left(4^{\circ} \mathrm{C}\right)$. Extracts were performed with $0.6 \mathrm{M}$ perchloric acid supplemented with $25 \mathrm{mM}$ EDTA-Na ${ }^{+}$and then centrifuged at $20,800 \times g$ for $2 \mathrm{~min}$ at $4{ }^{\circ} \mathrm{C}$ to remove cell debris. The resulting pellet was solubilized with $1 \mathrm{M} \mathrm{NaOH}$ and further analyzed for total protein content by the Bio-Rad Protein assay. After neutralization with $3 \mathrm{M} \mathrm{KOH} / 1.5 \mathrm{M}$ Tris, samples were centrifuged at $20,800 \times g$ for $5 \mathrm{~min}$, at $4{ }^{\circ} \mathrm{C}$. The resulting supernatants were assayed for:

1. ATP, ADP, and AMP determination by separation in a reverse-phase high-performance liquid chromatography, with detection at $254 \mathrm{~nm}$, as described previously [37]. The chromatographic apparatus used was a BeckmanSystem Gold controlled by a computer. The detection wavelength was $254 \mathrm{~nm}$, and the column used was a Lichrospher $100 \mathrm{RP}-18(5 \mu \mathrm{m})$. An isocratic elution with $100 \mathrm{mM}$ phosphate buffer $\left(\mathrm{KH}_{2} \mathrm{PO}_{4}\right), \mathrm{pH} 6.5$, and $1 \%$ methanol was performed with a flow rate of $1 \mathrm{~mL} / \mathrm{min}$. Peak identity was determined by following the retention time of standards.

2. Intracellular phosphocreatine levels, by following $\mathrm{NADP}^{+}$reduction at $339 \mathrm{~nm}$, mediated by ATP production by creatine kinase, in the presence of hexokinase and glucose-6-phosphate dehydrogenase (G6PD), using a Microplate Spectrophotometer SpectraMax Plus 384
(Molecular Devices, USA), according to a previously described method [38]. The results were expressed in picomole phosphocreatine/milligram protein.

3. Intracellular pyruvate levels using the Pyruvate Assay Kit (Abcam). In this assay, pyruvate is oxidized by pyruvate oxidase, further generating a fluorescent compound. The fluorescence was measured by fluorimetry $\left(E_{\mathrm{x}} / E_{\mathrm{m}}=535 /\right.$ $587 \mathrm{~nm}$ ), and the intensity was proportional to pyruvate content.

Assessment of Intracellular Lactate

Treated or untreated HD and CTR lymphoblasts were washed with ice-cold PBS and extracted with $0.6 \mathrm{M}$ perchloric acid supplemented with $25 \mathrm{mM}$ EDTA-Na ${ }^{+}$. Cell extracts were centrifuged at $20,800 \times g$ for $5 \mathrm{~min}$ at $4{ }^{\circ} \mathrm{C}$ to remove cell debris (as in [18]). Intracellular lactate levels were determined using the Lactate Assay Kit (Abcam). In this assay, lactate is oxidized by lactate dehydrogenase to generate pyruvate and NADH, which in turn reacts with WST to produce a colored product (formazan; $\mathrm{OD}=450 \mathrm{~nm}$ ).

$\mathrm{O}_{2}$ Consumption

HD or CTR lymphoblasts, incubated in the absence or in the presence of $0.1 \mathrm{nM}$ insulin or $0.1 \mathrm{nM}$ IGF-1, were washed and re-suspended in Krebs buffer containing (in $\mathrm{mM}$ ): $132 \mathrm{NaCl}, 4$ $\mathrm{KCl}, 1 \mathrm{CaCl}_{2}, 1.2 \mathrm{NaH}_{2} \mathrm{PO}_{4}, 1.4 \mathrm{mM} \mathrm{MgCl}$, 6 glucose, 10 HEPES, and aliquots containing $5 \times 10^{6}$ cells placed in an oxygen electrode chamber (DW1, Clark electrode, Hansatech, UK), after calibration for dissolved oxygen. After recording the basal rate of oxygen consumption (in $\mathrm{nmol} \mathrm{mL} \mathrm{min}^{-1}$ ), maximum respiration was assessed by adding $2.5 \mu \mathrm{M}$ carbonyl cyanide 3-chlorophenylhydrazone (CCCP) plus $2 \mu \mathrm{g} / \mathrm{mL}$ oligomycin to the reaction medium. $\mathrm{KCN}(700 \mu \mathrm{M})$ was added at the end of the experiment to confirm $\mathrm{O}_{2}$ consumption by mitochondria.

Assay of Enzymatic Activities of Mitochondrial Electron Transport Chain

Mitochondrial crude fractions prepared from treated versus non-treated HD or CTR lymphoblasts were obtained as described in "Preparation of Total, Mitochondrial, and Cytosolic-Enriched Fractions and Western Blotting" (without supplementation with DTT, PMSF, or protease inhibitor cocktail) and used for further analysis of enzymatic activities of mitochondrial electron transport chain complexes.

NADH-Ubiquinone Oxidoreductase Assay Complex I activity was determined at $340 \mathrm{~nm}$ by following the decrease in $\mathrm{NADH}$ absorbance due to ubiquinone reduction to ubiquinol 
[39]. Complex I activity was expressed in nanomoles per minute per milligram protein and corresponds to the rotenone sensitive rate.

Succinate-Ubiquinone Oxidoreductase Assay Complex II activity was monitored at $600 \mathrm{~nm}$ by following the reduction of 6,6-dichlorophenolindophenol (DCPIP) by the ubiquinol resulting from this reaction [40]. Complex II activity was expressed in nanomoles per minute per milligram protein and corresponds to the thenoyltrifluoroaceton (TTFA) sensitive rate.

Ubiquinol-Cytochrome C Reductase Assay Complex III activity was monitored at $550 \mathrm{~nm}$ by following the ubiquinol reduction of cytochrome $\mathrm{c}$. The assay was started by adding the sample to the reaction mixture (in mM: $35 \mathrm{~K}_{2} \mathrm{HPO}_{4}$, $\mathrm{pH}$ 7.2, 1 EDTA, $5 \mathrm{MgCl}_{2}, 1 \mathrm{KCN}, 5 \mu \mathrm{M}$ rotenone) containing $15 \mu \mathrm{M}$ cytochrome $\mathrm{c}$ and $15 \mu \mathrm{M}$ ubiquinol, at $30^{\circ} \mathrm{C}$. Complex III activity was expressed in rate constant $(k)$ per minute per milligram of protein.

Cytochrome c Oxidase Assay Complex IV activity was determined at $550 \mathrm{~nm}$ by measuring the oxidation of reduced cytochrome $\mathrm{c}$ by cytochrome c oxidase [41]. Complex IV activity was expressed in rate constant $(k)$ per minute per milligram of protein.

All enzyme activity was corrected for citrate synthase (CS) activity. For citrate synthase assay, CS activity was performed at $412 \mathrm{~nm}$ following the reduction of 5,5'-dithio-bis(2nitrobenzoic acid) in the presence of acetyl-CoA and oxaloacetate [42]. CS activity was expressed in nanomoles per minute per milligram protein.

\section{$\mathrm{TMRM}^{+}$Fluorescence}

Mitochondrial membrane potential was assessed using the cationic fluorescent probe $\mathrm{TMRM}^{+}$, which accumulates predominantly in polarized mitochondria. Thus, the variation of $\mathrm{TMRM}^{+}$retention was studied in order to estimate changes in mitochondrial membrane potential. Following a washing step, HD or CTR lymphoblasts, treated or not with insulin or IGF1 , were incubated in Krebs medium containing $300 \mathrm{nM}$ $\mathrm{TMRM}^{+}$(quench mode) for $1 \mathrm{~h}$ at $37^{\circ} \mathrm{C}$. Basal fluorescence (540 nm exCitation and $590 \mathrm{~nm}$ emission) was measured using a microplate reader Spectrofluorometer Gemini EM (Molecular Devices, USA), for $4 \mathrm{~min}$, followed by the addition of $2.5 \mu \mathrm{M}$ CCCP plus $2 \mu \mathrm{g} / \mathrm{mL}$ oligomycin to produce maximal mitochondrial depolarization.

Intracellular $\mathrm{Ca}^{2+}$ Recordings

HD or CTR lymphoblasts, incubated in the absence or in the presence of $0.1 \mathrm{nM}$ insulin or $0.1 \mathrm{nM}$ IGF-1, were incubated in Krebs medium containing the fluorescent probe Fura-2/AM $(10 \mu \mathrm{M})$ in the incubator chamber, at $37^{\circ} \mathrm{C}$, for $30 \mathrm{~min}$. After a washing step, intracellular $\mathrm{Ca}^{2+}$ levels were measured in basal conditions or in response to $1 \mathrm{mM}$ hydrogen peroxide $\left(\mathrm{H}_{2} \mathrm{O}_{2}\right)$ and/or $2 \mu \mathrm{M}$ CCCP plus $2 \mu \mathrm{g} / \mathrm{mL}$ oligomycin, using a Spectrofluorometer Gemini EM (Molecular Devices, USA), with 340/380 nm excitation and 510-nm emission wavelengths.

\section{Fluorescence Imaging}

HD or CTR lymphoblasts, incubated in the absence or presence of $0.1 \mathrm{nM}$ insulin or $0.1 \mathrm{nM}$ IGF-1, and further adhered to glass coverslips, as described in "Cell Lines Culture and Treatment," were exposed to $500 \mathrm{nM}$ MitoTraker Red CMXRos (MtT Red) in Krebs medium during $40 \mathrm{~min}$, at $37^{\circ} \mathrm{C}$. Cells were fixed with $4 \%$ paraformaldehyde for $20 \mathrm{~min}$ and then permeabilized with $0.2 \%(v / v)$ Triton X-100 in PBS. After a washing step, cells were blocked with $3 \%(w / v)$ bovine serum albumin and then incubated with TOM-20 (1:200) primary antibody and further with antimouse Alexa Fluor 488 (1:200) secondary antibody. Finally, the coverslips were mounted using Dako fluorescent mounting medium and examined using a Zeiss LSM S10 META confocal microscope (Carl Zeiss, Oberkochen, Germany) equipped with a $63 \mathrm{x} / 1,4$ Plan-ApoChromat objective. The lasers used were $\operatorname{argon} / 2(488 \mathrm{~nm})$ and DPSS 561-10 $(561 \mathrm{~nm})$. The acquisition of images was performed in the LSM 510 software.

\section{Data Analysis and Statistics}

Data were expressed as the mean \pm SEM of the number of experiments indicated in the figure legends. Comparisons among multiple groups were performed by two-way ANOVA, followed by Bonferroni post hoc test. Student's $t$ test was also performed for comparison between two Gaussian populations, as described in figure legends. Significance was accepted at $p<0.05$.

\section{Results}

IGF-1 Stimulates Akt and ERK Signaling Pathways

In previous studies, Akt was shown to be downregulated through cleavage by caspase- 3 in both animal models and HD patients at late stages of the disease [43]. This was associated with a deregulation of IGF-1/Akt signaling pathway caused by $\mathrm{mHtt}$ along the course of the disease [21]. Using lymphoblasts cell lines derived from HD patients and control siblings, we evaluated the insulin/IGF-1 signaling pathways. Our results demonstrate that IR,IGF-1R phosphorylation at Tyr1158, 1162, and 1163, previously described to 
reflect their activation [24, 44], was significantly decreased in HD patient's lymphoblasts (Fig. 1ai), whereas no significant changes were observed in IR,IGF-1R protein levels (Fig. 1a, ii). Exposure to IGF-1 (0.1 nM) enhanced IR,IGF-1R activation in HD cells by about 2-fold, whereas no changes in IR,IGF-1R activation were observed in the presence of insulin $(0.1 \mathrm{nM})$. In addition, we found a significant decrease in Akt and ERK42/44 phosphorylation in HD lymphoblasts, which were prevented by insulin and IGF-1 (Fig. 1b, i, iii and c, i, iii), suggesting an activation of PI3K/Akt and Ras/ERK signaling pathways in HD human lymphoblasts subjected to insulin and, particularly, IGF-1 treatment. Importantly, at IR, the rank order of affinity to insulin $(\sim 1 \mathrm{nM})>>$ IGF-I (100-500-fold), whereas at IGF-1R IGF-1 ( 1 nM) >>insulin (100-500-fold)
[45]. Therefore, low nanomolar concentrations of insulin and IGF-1 may activate each receptor subtype.

Given the decrease in Akt activation in HD lymphoblasts, we measured phosphorylated and total levels of Akt downstream proteins. Mammalian target of rapamycin (mTor) total protein levels were significantly decreased in HD cells, by about $50 \%$, compared to the CTR (Fig. 1d, ii). Interestingly, mTor activation was significantly increased in HD lymphoblasts (by $155 \%$, Fig. 1d, $i$ ), but further exposure to insulin or IGF-1 had no significant additional effect. Moreover, no significant differences were observed in Foxo-1 Ser256 phosphorylation, a target of Akt (Fig. 1e). In addition, the Ser/Thr kinase GSK-3 $\beta$, which has the potential to modulate blood glucose levels [46], was not altered in HD lymphoblasts. a. $\boldsymbol{i}$

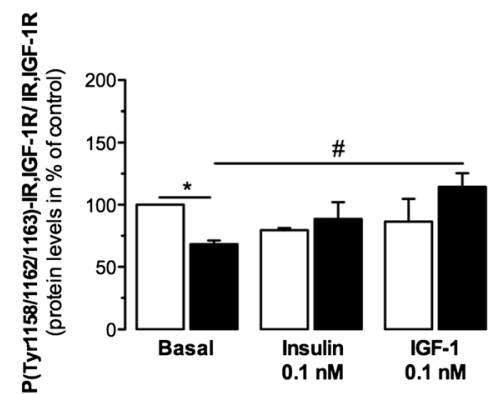

b. $i$

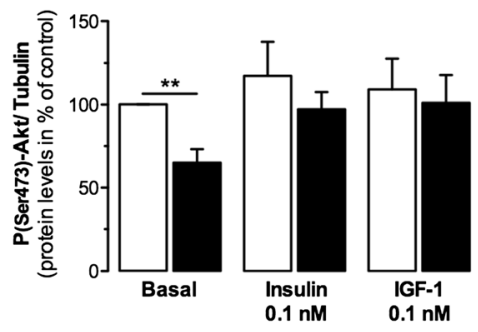

c. $i$

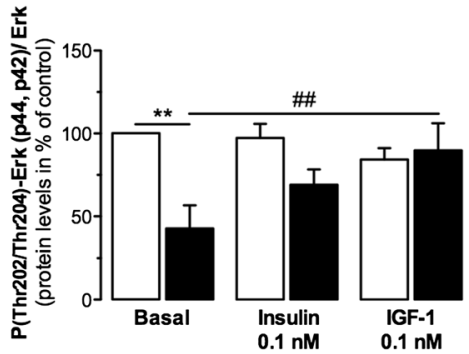

Fig. 1 IGF-1 and insulin mediated activation of IR,IGF-1R signaling pathways. CTR or HD lymphoblasts were untreated (basal) or treated with $0.1 \mathrm{nM}$ insulin or IGF-1 in culture medium (RPMI-1640) for $24 \mathrm{~h}$ at $37^{\circ} \mathrm{C}$. Total cell lysates were electrophoresed on $10 \%$ SDS-PAGE and probed for phosphorylated proteins with anti-P(Y1158/Y1162/Y1163)IR,IGF-1R (a, $i$ ), anti-P(Ser473)-Akt (b, $i$ ), anti-P(Thr202/Thr204)-ERK (c, $i$ ), anti-P(Ser2448)-mTor (d, $i$ ), anti-P(Ser256)-Foxo1 (e, $i$ ), and anti$\mathrm{P}($ Tyr216)-GSK3 $\beta$ (f, $i$ ) selective antibodies, followed by reprobing for total protein with anti-IR,IGF-1R (a, ii), anti-Akt (b, ii), anti-ERK (c, ii), anti-mTor (d, ii), anti-FOXO1 (e, ii), and anti-GSK3 $\beta$ (f, ii) selective a. iii

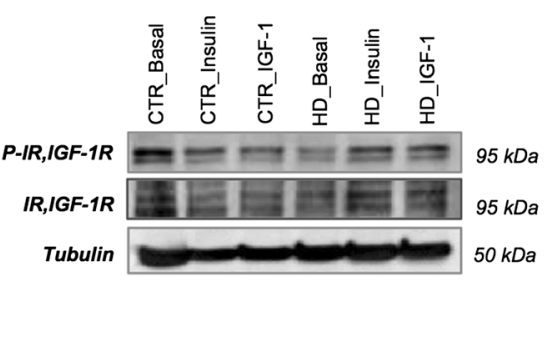

b. iii

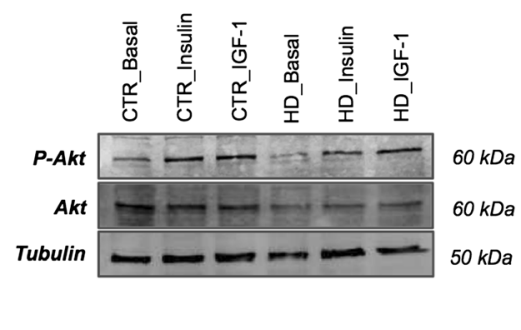

c. iii

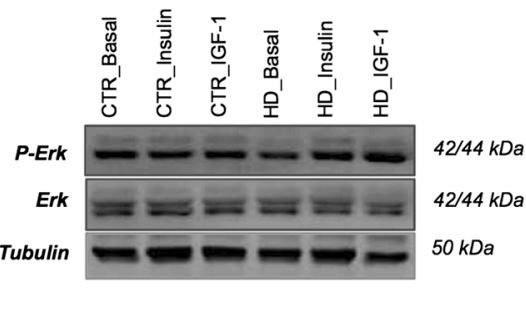

antibodies. All total proteins were normalized with anti-tubulin antibody. Data are the mean \pm SEM from three to six independent experiments, expressed as percentage of CTR (under basal conditions), considering $0.59 \pm 0.01$ (a, $i), 0.32 \pm 0.04$ (a, ii), $0.57 \pm 0.28$ (b, i), $1.36 \pm 0.37$ (b, ii), $5.59 \pm 2.41$ (c, $i), 0.08 \pm 0.04$ (c, $i i), 0.55 \pm 0.11$ (d, $i), 1.88 \pm 0.74$ (d, ii), $1.62 \pm 0.49$ (e, $i), 0.91 \pm 0.34$ (e, $i i), 2.24 \pm 0.39$ (f, $i$ ), and $0.11 \pm 0.02$ (f, $i i)$ INT $/ \mathrm{mm}^{2}$ as $100 \%$. Statistical analysis: ${ }^{\mathrm{t}} P<0.05,{ }^{\mathrm{tt}} P<0.01$ vs respective CTR (Student's $t$ test); ${ }^{*} P<0.05,{ }^{*} P<0.01$ vs respective CTR; ${ }^{*} P<0.05$, ${ }^{\# \#} \mathrm{P}<0.01$ vs untreated HD (two-way ANOVA, followed by Bonferroni post hoc test) 
d. $i$

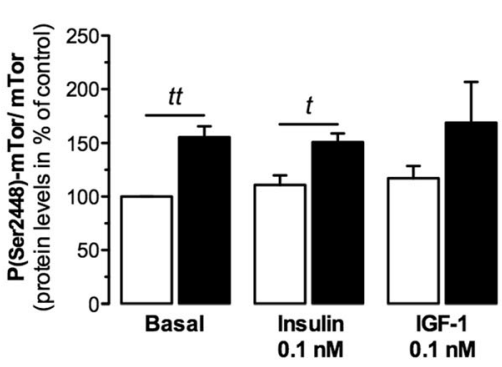

e.

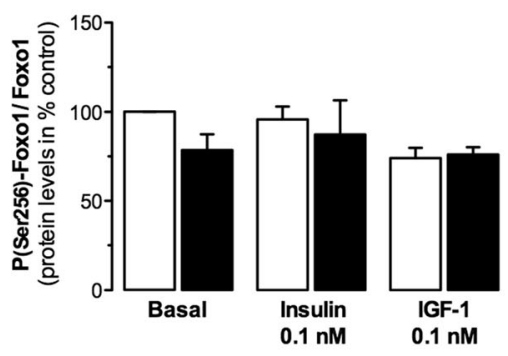

f. $i$

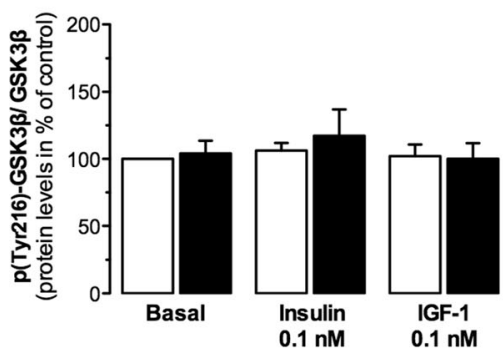

d. ii

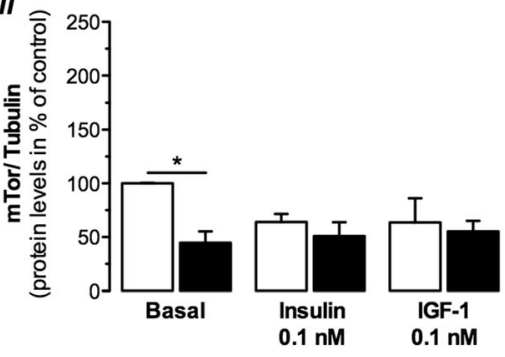

d. iii

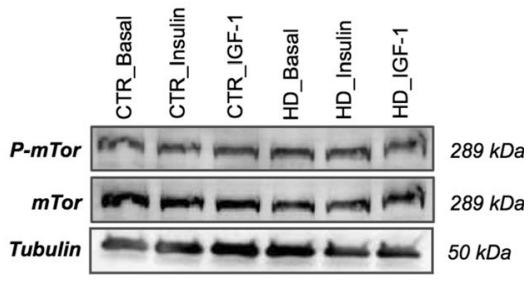

e. $i$

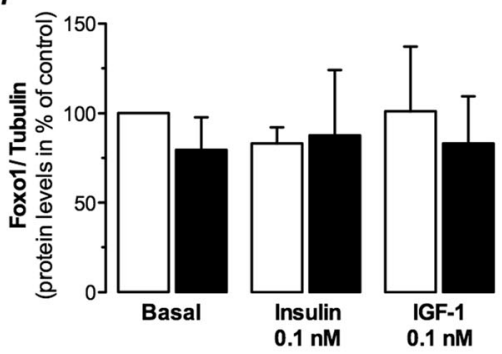

e. $i i i$

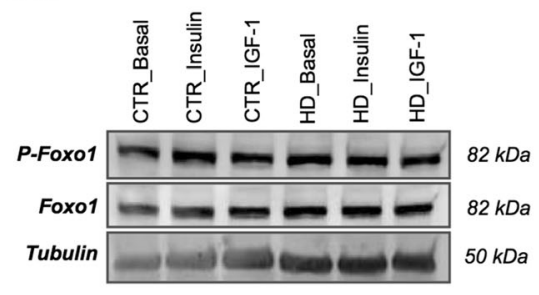

Fig. 1 (continued)

f. $i$

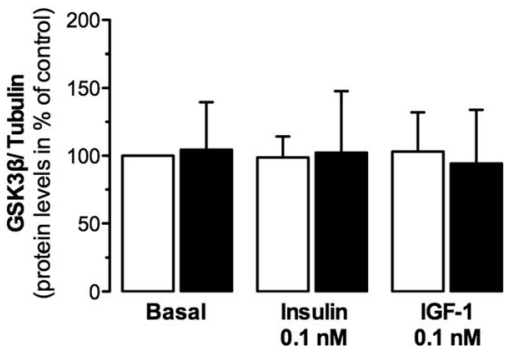

f. iii

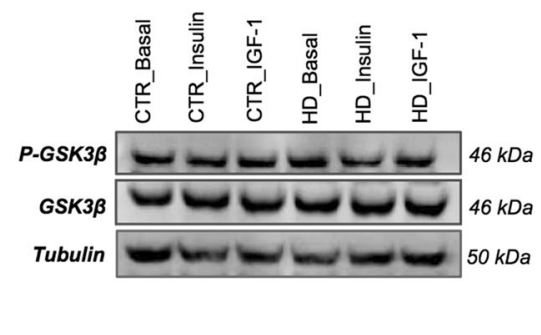

Indeed, their enzymatic activities can the negatively regulated by Akt-mediated phosphorylation at Ser9, and positively regulated by Tyr216 phosphorylation [47]; however, we also found no differences in the levels of P(Tyr216)-GSK-3 $\beta$ (Fig. 1f).

Insulin and IGF-1 Promote Huntingtin Phosphorylation

Specific neuroprotective effect of IGF-1/Akt in HD appears to be mediated by direct phosphorylation of Htt by Akt at Ser421, blocking mHtt-induced cell death and inhibiting intranuclear inclusion formation [21,30]. Figure 2 shows that decreased P(Ser421)-Htt in HD lymphoblasts is completely rescued by insulin and IGF-1 (both at $0.1 \mathrm{nM}$ ) (Fig. 2a). Although there was a decrease in phosphorylation, Htt protein levels remained unchanged in HD and CTR cells (Fig. 2b) and upon exposure to insulin or IGF-1 (data not shown).

Insulin and IGF-1 Prevent Impairment of Energy Metabolism

We further analyzed the effect of insulin and IGF-1 on cellular adenine nucleotides, ATP, ADP, and AMP. HD lymphoblasts exhibited a decrease in ATP levels and an increase in ADP and AMP levels, compared to CTR lymphoblasts (Fig. 3a, i-iii).
Following incubation with $0.1 \mathrm{nM}$ insulin or IGF-1, a significant increase in ATP levels was observed in HD lymphoblasts, which appeared to derive from ADP and AMP (Fig. 3a, i-iii). Concomitantly with ATP decrease, a significant decrease in phosphocreatine levels was observed in HD, compared to CTR lymphoblasts, which were completely recovered upon treatment with insulin or IGF-1 (Fig. 3b). Moreover, the amount of lactate was shown to be significantly higher in untreated HD cells, when compared to CTR cells (Fig. 3d); insulin or IGF-1 (0.1 nM) caused a decrease in lactate levels in HD lymphoblasts. The intracellular levels of lactate in CTR cells were not significantly affected in the presence of insulin or IGF-1. Although there were significant alterations in lactate levels in HD cells, no visible changes were observed in pyruvate levels (Fig. $3 \mathrm{c}$ ).

\section{IGF-1/P-Htt Pathway Recovers Mitochondrial Function} in HD Lymphoblasts

There are several evidences that mitochondrial dysfunction plays a critical role in HD pathogenesis [7, 17, 18]. In order to evaluate whether mitochondrial dysfunction can be the source of lower ATP levels, we assessed $\mathrm{O}_{2}$ consumption in HD and CTR lymphoblasts (Fig. 4a-c). Under basal conditions, HD 
a. $i$

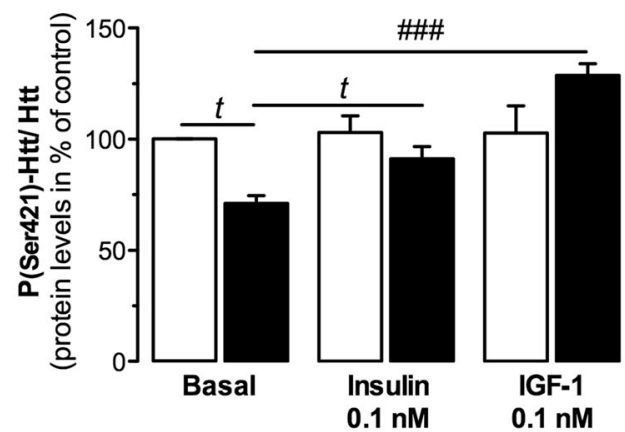

b. $i$

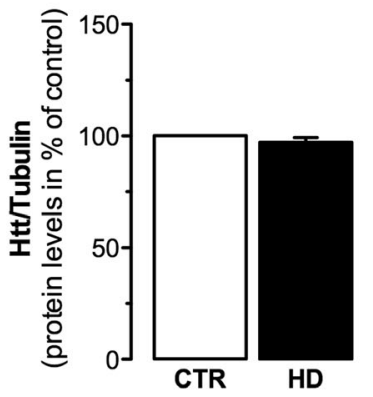

a. ii

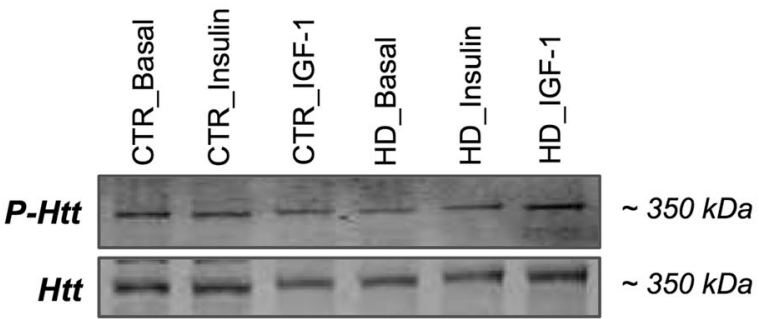

b ii

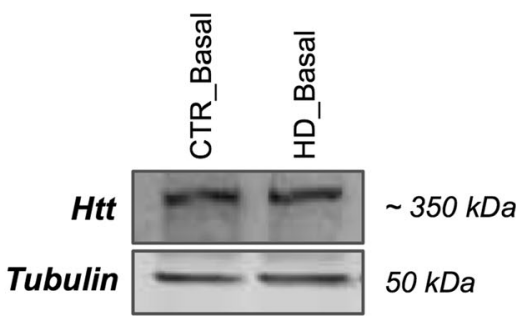

Fig. 2 IGF-1 and insulin promote huntingtin phosphorylation in HD lymphoblasts. CTR or HD lymphoblasts were untreated (basal) or treated with $0.1 \mathrm{nM}$ insulin or IGF-1 in culture medium (RPMI-1640) for $24 \mathrm{~h}$ at $37^{\circ} \mathrm{C}$. Levels of P(Ser421)Htt (a) and Htt (b) were analyzed by Western blotting. Data are the mean \pm SEM from four independent experiments,

lymphoblasts showed a lower rate of $\mathrm{O}_{2}$ consumption compared to CTR lymphoblasts (Fig. 4a), suggesting decreased activity of mitochondrial respiratory chain, which was expressed as percentage of CTR, considering a $2.08 \pm 0.39 \mathrm{INT} / \mathrm{mm}^{2}$ and b $27.17 \pm 1.03 \mathrm{INT} / \mathrm{mm}^{2}$ as $100 \%$. Statistical analysis: ${ }^{\mathrm{t}} P<0.05$ vs respective CTR (Student's $t$ test); ${ }^{\# \#} P<0.001$ vs untreated HD (two-way ANOVA, followed by Bonferroni post hoc test)

prevented by pre-exposure to $0.1 \mathrm{nM} \mathrm{IGF-1,} \mathrm{but} \mathrm{not} \mathrm{by} \mathrm{insulin}$ (Fig. 4a). Maximal $\mathrm{O}_{2}$ consumption, defined in the presence of CCCP (mitochondrial uncoupler) plus oligomycin (ATP a. $\boldsymbol{i}$

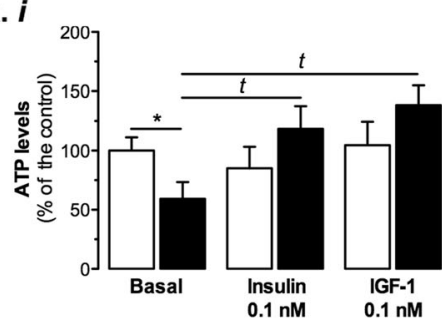

b.

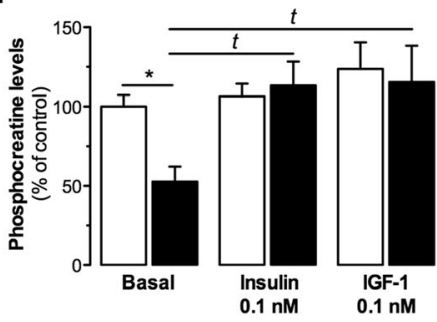

a. ii

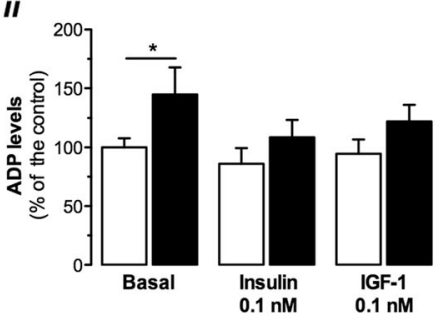

c.

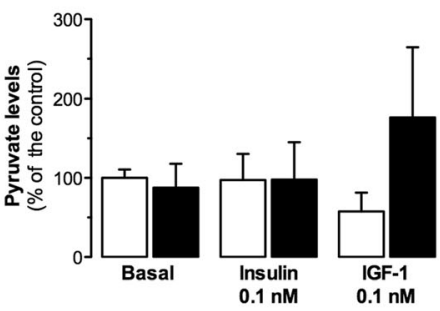

a. $i i j$

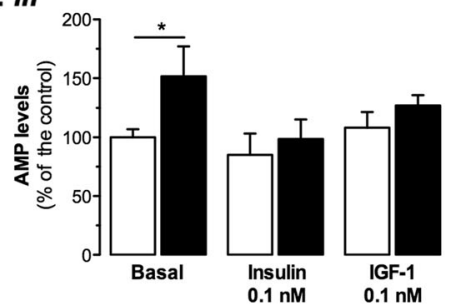

d.

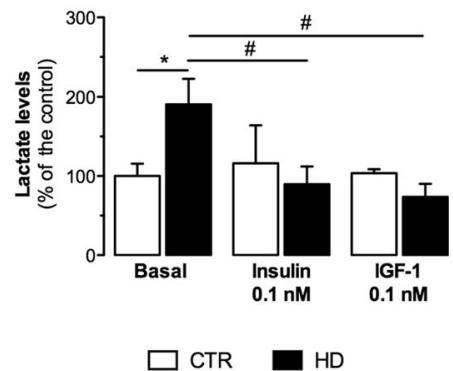

Fig. 3 IGF-1 and insulin rescued energy metabolism in HD lymphoblasts. CTR or HD lymphoblasts were untreated (basal) or treated with $0.1 \mathrm{nM}$ insulin or IGF-1 in culture medium (RPMI-1640) for $24 \mathrm{~h}$ at $37^{\circ} \mathrm{C}$. Energy metabolism was evaluated by determining levels of ATP (a.i), ADP (a, ii), AMP (a, iii), phosphocreatine (b), pyruvate (c), and lactate (d). Data are the mean \pm SEM from four independent experiments performed in duplicates, expressed as the $\%$ of CTR, considering a $1.3 \pm$
$0.3 \mathrm{nmol} / \mathrm{mg} \operatorname{prot}(i), 1.4 \pm 0.2 \mathrm{pmol} / \mathrm{mg} \operatorname{prot}(i i), 1.6 \pm 0.3 \mathrm{pmol} / \mathrm{mg}$ prot (iii), b $67.23 \pm 21.98 \mathrm{pmol} / \mathrm{mg}$ prot, c $17.01 \pm 1.0 \mathrm{nmol} / \mathrm{mg}$ prot as $100 \%$, and d $0.27 \pm 0.04 \mathrm{nmol} / \mathrm{mg}$ prot as $100 \%$. Statistical significance: ${ }^{\mathrm{t}} P<0.05$ vs untreated HD (Student's $t$ test); ${ }^{*} P<0.05$ vs CTR; ${ }^{*} P<0.05$ vs untreated HD (two-way ANOVA, followed by Bonferroni post hoc test) 


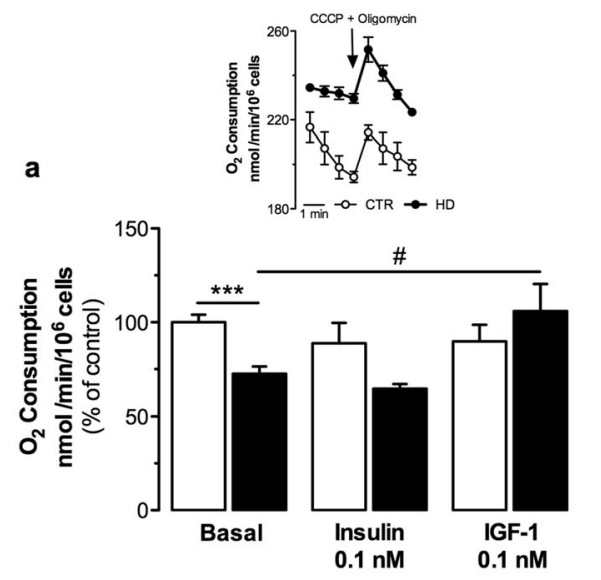

b

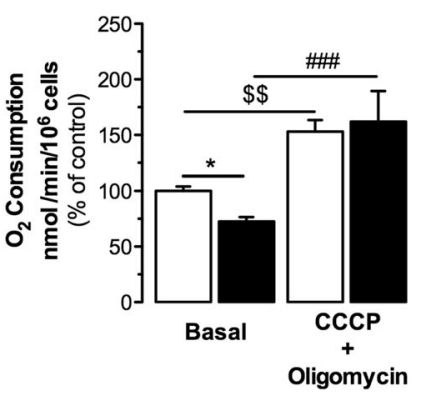

e

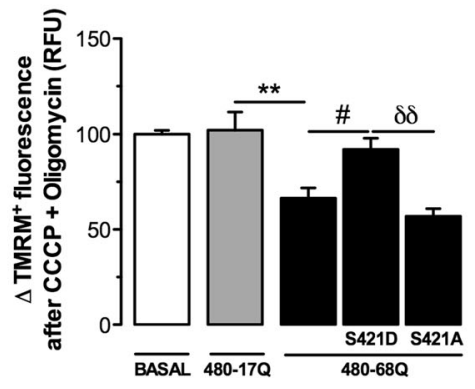

c

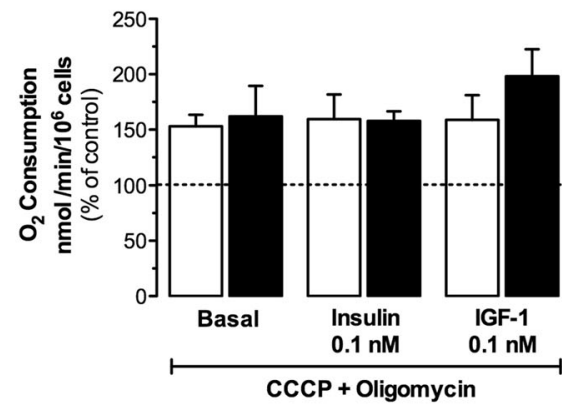

f

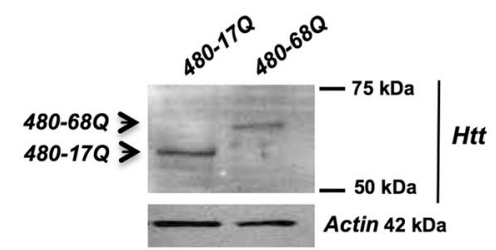

Fig. 4 IGF-1/P-Htt pathway ameliorates the rate of $\mathrm{O}_{2}$ consumption and mitochondrial membrane potential in HD lymphoblasts. CTR or HD lymphoblasts were untreated (basal) or treated with $0.1 \mathrm{nM}$ insulin or IGF-1 in culture medium (RPMI-1640) for $24 \mathrm{~h}$ at $37^{\circ} \mathrm{C}$. Basal recording rate of $\mathrm{O}_{2}$ consumption (a); maximum respiration was achieved after addition of CCCP plus oligomycin to untreated (b) or insulin and IGF-1 treated (c) CTR or HD lymphoblasts. TMRM ${ }^{+}$fluorescence was recorded after complete mitochondrial membrane depolarization (d, e). CTR lymphoblasts were transfected with plasmid constructs (480-17Q, 480-68Q, 480-68-S421D, and 480-68-S421A) previously described by Humbert et al. [21] $48 \mathrm{~h}$ before the experiment (e). Results were expressed as the

synthase inhibitor), as defined in Fig. 4a (insert) and b, was largely the same in CTR or HD lymphoblasts, in the absence or presence of insulin or IGF-1 (Fig. 4c).

We further evaluated mitochondrial membrane potential $\left(\Delta \psi_{\mathrm{m}}\right)$ before and after complete mitochondrial depolarization with CCCP plus oligomycin (Fig. 4d, insert). HD lymphoblasts exhibited a lower mitochondrial retention of $\mathrm{TMRM}^{+}$, largely suggesting lower $\Delta \psi_{\mathrm{m}}$, compared to CTR lymphoblasts; however, this decrease became insignificant in the present of $0.1 \mathrm{nM}$ IGF-1 (Fig. 4d), suggesting an amelioration of mitochondrial function, in accordance with the $\mathrm{O}_{2}$ consumption (Fig. 4a). Under the same experimental conditions, insulin had no significant effects on $\Delta \psi_{\mathrm{m}}$. These observations were further confirmed by qualitative fluorescence imaging with MtT Red (Fig. 5). MtT Red is an $\Delta \psi_{\mathrm{m}}$-sensitive difference between the increase of $\mathrm{TMRM}^{+}$fluorescence upon addition of CCCP plus oligomycin and basal fluorescence values. Inserts show representative traces of $\mathrm{O}_{2}$ consumption (in a) or TMRM ${ }^{+}$fluorescence (in d). The presence of truncated wild-type Htt (17 polyQ) or mHtt (68 polyQ) was detected by Western blotting (f). Data are the mean \pm SEM of three to four experiments performed in duplicates or triplicates. Statistical analysis: ${ }^{\mathrm{t}} P<0.05$ vs untreated HD (Student's $t$ test); ${ }^{*} P<0.05,{ }^{* *} P<0.01$ ${ }^{* * *} P<0.001,{ }^{\$} \$<<0.01$ vs untreated CTR; ${ }^{\#} P<0.05,{ }^{\# \# \#} P<0.001$ vs untreated HD; ${ }^{\delta \delta} P<0.01$ vs S421D HD (two-way ANOVA, followed by Bonferroni post hoc test)

positively charged fluorescent probe that is rapidly taken up into the negatively charged mitochondria [48]. Our results show a decrease in MtT Red fluorescence in HD compared to CTR lymphoblasts (Fig. 5), thus reducing its colocalization with TOM20, a mitochondria marker that remains unchanged between genotypes (CTR vs HD) (Table 1). Moreover, IGF-1 treatment appears to effectively rescue the decrease in $\Delta \psi_{m}$ in HD cells, as observed by the increase in MtT Red fluorescence, in accordance with $\mathrm{TMRM}^{+}$fluorescence data. Interestingly, insulin appears to have the same effect as IGF-1 (Fig. 5), although these results have not been confirmed with $\mathrm{TMRM}^{+}$.

Considering these results, we hypothesized that beneficial effect of IGF-1 on mitochondrial function might be related with Htt phosphorylation. Therefore, we transfected CTR 
Fig. 5 IGF-1 and insulin rescue mitochondrial membrane potential in HD lymphoblasts. Representative confocal microscope images of CTR and HD lymphoblasts untreated (basal) or treated with $0.1 \mathrm{nM}$ insulin or IGF-1 for $24 \mathrm{~h}$, at $37^{\circ} \mathrm{C}$. Lymphoblasts were stained with MitoTraker Red CMXRos (MtT Red, $500 \mathrm{nM}$ ) (red) and antiTOM20 (green). Left Transmission image, middle left TOM20 signal, middle right $\mathrm{MtT}$ Red signal, right Merge image. Scale bar: $10 \mu \mathrm{m}$

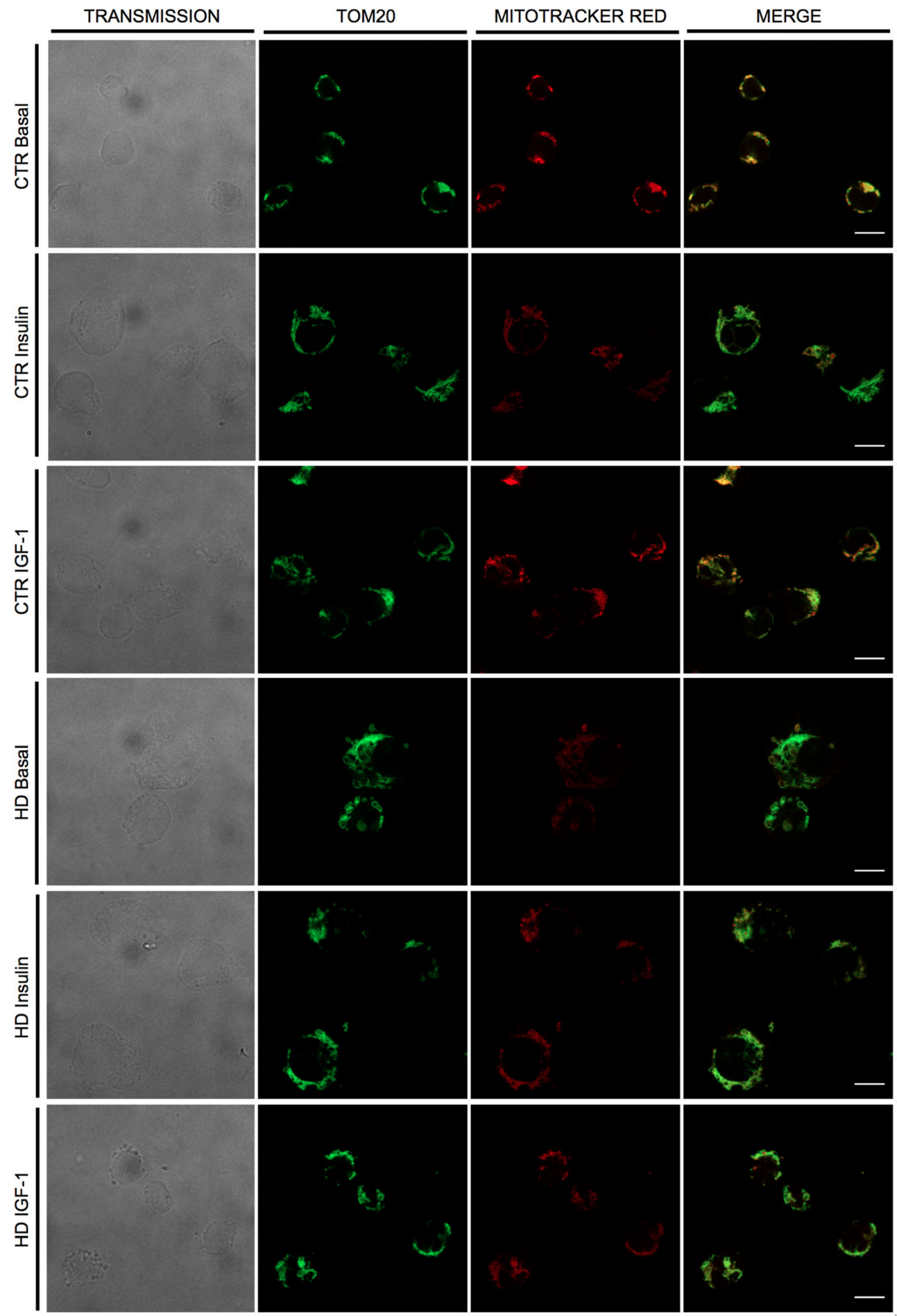

lymphoblasts with 480 amino acid-Htt fragments containing a stretch of 17 (480-17) or 68 (480-68) glutamines, being the efficiency of transfection confirmed by Western blotting (Fig. 4f). Moreover, two more constructs were transfected: one containing a serine to aspartate mutation at the 421 site, maintaining Htt constitutively phosphorylated (480-68S421D) and another one containing a serine to alanine mutation, thus inhibiting Htt phosphorylation (480-68-S421A). In accordance with data obtained in HD lymphoblasts, we observed a significant decrease in $\Delta \psi_{\mathrm{m}}$ in lymphoblasts transfected with 480-68 construct, compared with 480-17 transfected lymphoblasts. Constitutive Htt phosphorylation (S421D) was able to fully restore $\Delta \psi_{\mathrm{m}}$ in lymphoblasts carrying the mutant stretch; In contrast, serine to alanine mutation completely deregulated $\Delta \psi_{\mathrm{m}}$ (Fig. 4e). These data largely suggested that amelioration of mitochondrial function 
Table 1 Mitochondrial-relevant proteins in human HD and CTR lymphoblasts

\begin{tabular}{|c|c|c|}
\hline Proteins of interest & $\mathrm{CTR}(\operatorname{mean} \pm \mathrm{SEM})(n)$ & $\mathrm{HD}($ mean $\pm \mathrm{SEM})(n)$ \\
\hline \multicolumn{3}{|l|}{ Mitochondrial-encoded ETC subunits } \\
\hline Mitochondrial complex I (subunit, 20 kDa)/hsp60 (T) & $100.0 \pm 16.65(10)$ & $73.24 \pm 19.56(11)$ \\
\hline Mitochondrial complex I (subunit, $20 \mathrm{kDa}$ )/hsp60 (M) & $100.0 \pm 25.20(5)$ & $93.72 \pm 17.06(8)$ \\
\hline Mitochondrial complex IV (subunit SI)/hsp60 (T) & $100.0 \pm 13.35(5)$ & $87.73 \pm 12.55(4)$ \\
\hline Mitochondrial complex IV (subunit SI)/hsp60 (M) & $100.0 \pm 13.10(5)$ & $103.66 \pm 12.61(9)$ \\
\hline \multicolumn{3}{|l|}{ Nuclear-encoded ETC subunits } \\
\hline Mitochondrial complex I (subunit, 30 kDa)/hsp60 (T) & $100.0 \pm 2.13(6)$ & $98.03 \pm 12.00(8)$ \\
\hline Mitochondrial complex II (subunit, $70 \mathrm{kDa}$ )/hsp60 (T) & $100.0 \pm 15.58(9)$ & $93.00 \pm 15.78(11)$ \\
\hline \multicolumn{3}{|l|}{ Mitochondrial translocases and chaperones } \\
\hline Hsp60/tubulin (T) & $100.0 \pm 3.14(9)$ & $112.9 \pm 9.22(15)$ \\
\hline TOM20/hsp60 (M) & $100.0 \pm 0.11(3)$ & $97.39 \pm 36.98(3)$ \\
\hline TOM40/hsp60 (M) & $100.0 \pm 1.58(3)$ & $99.16 \pm 17.86(3)$ \\
\hline Prohibitin (PHB)/hsp60 (M) & $100.0 \pm 10.46(5)$ & $103.02 \pm 12.28(9)$ \\
\hline \multicolumn{3}{|l|}{ Transcription factors } \\
\hline Mitochondrial transcription factor (Tfam)/hsp60 (M) & $100.0 \pm 8.08(9)$ & $60.06 \pm 6.80(8)^{* *}$ \\
\hline p65/hsp60 (M) & $100.0 \pm 12.78(3)$ & $95.79 \pm 8.06(6)$ \\
\hline p53/hsp60 (M) & $100.0 \pm 13.19(3)$ & $94.39 \pm 15.96(9)$ \\
\hline \multicolumn{3}{|l|}{ Apoptotic proteins } \\
\hline Bax/hsp60 (M) & $100.0 \pm 3.48(3)$ & $90.14 \pm 27.42(3)$ \\
\hline Bax/tubulin (C) & $100.0 \pm 5.85(3)$ & $92.68 \pm 10.47(3)$ \\
\hline AIF/tubulin (T) & $100.0 \pm 9.161(5)$ & $82.74 \pm 6.74(4)$ \\
\hline Cytochrome c/hsp60 (M) & $100.0 \pm 9.12(6)$ & $65.97 \pm 6.55(4)^{*}$ \\
\hline Cytochrome c/tubulin (C) & $100.0 \pm 6.29(3)$ & $68.52 \pm 14.47(3)$ \\
\hline Cytochrome c/tubulin (T) & $100.0 \pm 0.00(3)$ & $70.30 \pm 0.78(3)^{* *}$ \\
\hline
\end{tabular}

Relative changes in the levels of mitochondrial- and nuclear-encoded proteins from total (T), mitochondrial (M) and/or cytosolic (C)-enriched fractions from human HD or CTR lymphoblasts. Proteins of the mitochondria electron transport chain, mitochondrial translocases of the outer membrane, 20 and 40 subunits (TOM20 and TOM40, respectively) and the mitochondrial chaperones hsp60 and prohibitin (PHB), transcription factors, and apoptotic proteins. The results are the mean $\pm \mathrm{SEM}$ of the indicated number of experiments (in brackets) normalized to hsp60 or tubulin (as indicated) and are represented as the $\%$ of the CTR group

$* P<0.05 ; * * P<0.01$ vs CTR (by the Student's $t$ test)

induced by IGF-1 in HD lymphoblasts occurs through phosphorylation of $\mathrm{mHtt}$ at Ser421.

Unchanged Protein Expression or Activity of Mitochondrial Complexes, But Decreased Cytochrome c in HD Lymphoblast Mitochondria-Effect of Insulin and IGF-1

After observing the decrease in ATP production and oxygen consumption in HD lymphoblasts, we sought for changes in activity and expression of mitochondrial respiratory complexes and proteins. No significant differences in the activity of mitochondrial respiratory chain complexes I-IV were observed in HD versus CTR lymphoblasts (Fig. 6), corroborating previous data [11]. Table 1 shows that there are no statistical significant differences in protein levels of both mitochondrial- and nuclear-encoded subunits from electron transport chain (Table 1) either.
We also examined the relative changes in other mitochondrial proteins, including subunits of transporter outer membrane (TOM) complex, hsp60, and prohibitin, as well as mitochondrial transcription factors, namely, mitochondrial transcription factor A (Tfam), p65 and p53, but apart from Tfam, no statistical differences were found between HD and CTR cells (Table 1). Tfam is the major transcription factor of mitochondrial DNA (mtDNA) and also appears to protect mtDNA since it packages mtDNA into DNA-protein aggregates called mitochondrial nucleoids [49]. Tfam stimulates the transcription of the majority mitochondrial-encoded subunits [50]; nevertheless, complex I subunit of $20 \mathrm{kDa}$ and complex IV subunit SI were not altered in HD lymphoblasts (Table 1). Despite this, we cannot exclude the hypothesis that this factor could be a key protein in mitochondrial dysfunction in this HD cell model.

Previous data in our lab showed mitochondrial-associated cell death in a peripheral model expressing $\mathrm{mHtt}$, through the 
Fig. 6 Mitochondrial respiratory chain specific activities of complexes I-IV are unchanged in HD lymphoblasts. CTR or HD lymphoblasts were untreated (basal) or treated with $0.1 \mathrm{nM}$ insulin or IGF-1 in culture medium (RPMI-1640) for $24 \mathrm{~h}$ at $37^{\circ} \mathrm{C}$. The activities of mitochondrial complexes I (a), II (b), III (c), and IV (d) were normalized to cytrate synthase. Data are expressed as the mean \pm SEM from three to six independent experiments a.

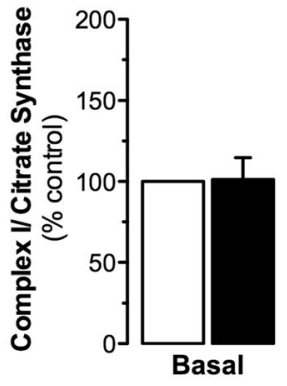

c.

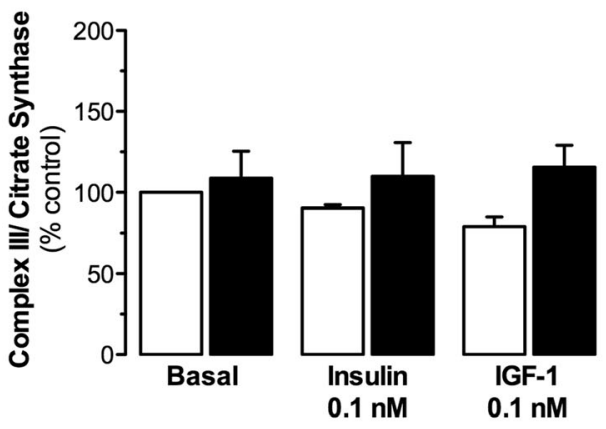

b.

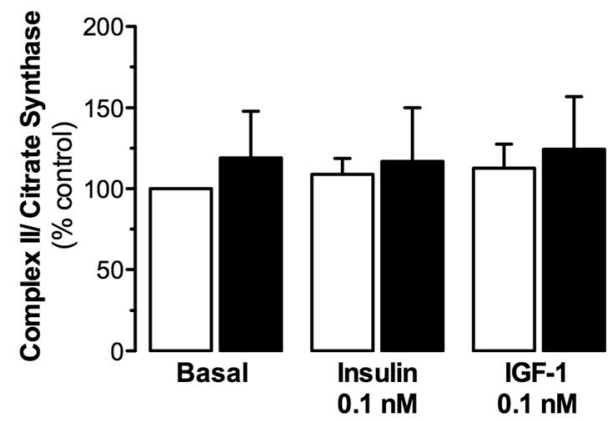

d.

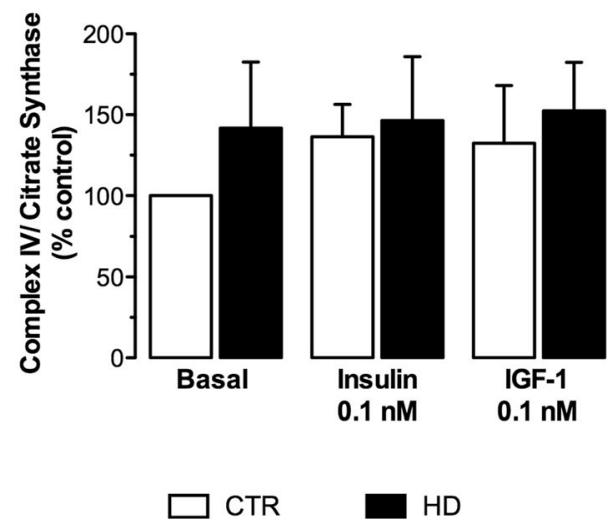

activation of caspases, release of cytochrome $\mathrm{c}$ and AIF from mitochondria, and increased $\mathrm{Bcl}-2$-associated $\mathrm{X}$ protein (Bax) levels [18]. Bearing this in mind, we also analyzed the levels of the apoptotic proteins Bax, AIF, and cytochrome $\mathrm{c}$ in HD lymphoblasts. A significant decline was detected in cytochrome c protein levels in mitochondria from HD lymphoblasts, which did not account for by an increase in the protein in the cytosol (Table 1), precluding any evidence for mitochondrial-driven apoptosis in these peripheral cells. Accordingly, cytochrome c total levels were significantly decreased in $\mathrm{HD}$ cells, largely suggesting that deficits in $\mathrm{O}_{2}$ consumption can be due to decreased shuttling of electrons at cytochrome c level. Moreover, treatment with $0.1 \mathrm{nM}$ IGF1 rescued the decrease in cytochrome $\mathrm{c}$ in HD lymphoblasts (Fig. 7), revealing a protein modification at the electron transport chain that contributes for boosting mitochondrial function in the presence of this neurotrophic factor.

\section{Altered Mitochondrial $\mathrm{Ca}^{2+}$ Accumulation in HD \\ Lymphoblasts - Role of Insulin and IGF-1}

Under the same experimental conditions, we measured the intracellular free levels of $\mathrm{Ca}^{2+}\left(\mathrm{Ca}^{2+}{ }_{\mathrm{i}}\right)$ and the capacity of mitochondria to retain the ion. HD cells showed increased intracellular $\mathrm{Ca}^{2+}$, which was exacerbated upon exposure to IGF-1 (Fig. 8a). Moreover, complete mitochondrial depolarization with CCCP plus oligomycin elicited a decrease in $\mathrm{Ca}^{2+}$ release from mitochondria in HD lymphoblasts compared to CTR cells, highly suggestive of decreased mitochondria capacity to retain $\mathrm{Ca}^{2+}$ in HD lymphoblasts (Fig. 8b). However,

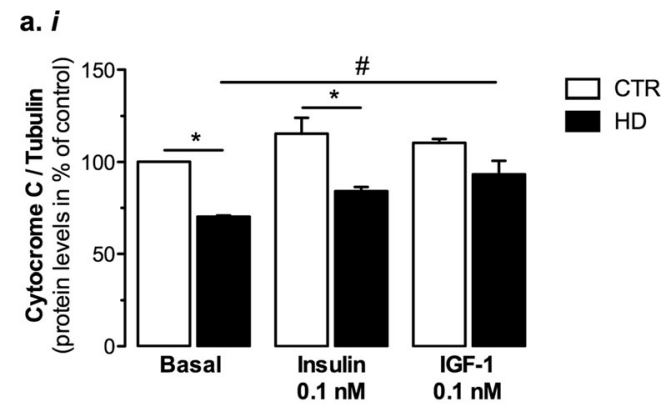

a. ii

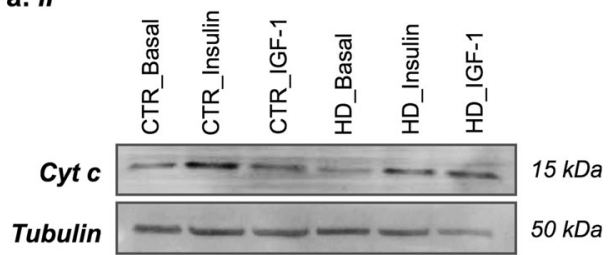

Fig. 7 IGF-1 enhances the levels of cytochrome $\mathrm{c}$ in HD lymphoblasts. CTR or HD lymphoblasts were untreated (basal) or treated with $0.1 \mathrm{nM}$ insulin or IGF-1 in culture medium (RPMI-1640) for $24 \mathrm{~h}$ at $37^{\circ} \mathrm{C}$. Total expression levels of cytochrome $\mathrm{c}$ were analyzed by Western blotting on $15 \%$ SDS-PAGE and reprobed for tubulin (a $i, i i)$. Data are the mean \pm SEM from three independent experiments, expressed as percentage of CTR, considering $0.48 \pm 0.06 \mathrm{INT} / \mathrm{mm}^{2}$ as $100 \%$. Statistical analysis: ${ }^{*} P<0.05$ vs respective CTR; ${ }^{\#} P<0.05$ vs untreated HD (two-way ANOVA, followed by Bonferroni post hoc test) 
Fig. 8 IGF-1 and insulin ameliorate mitochondrial $\mathrm{Ca}^{2+}$ accumulation in HD lymphoblasts subjected to $\mathrm{H}_{2} \mathrm{O}_{2}$. CTR or HD lymphoblasts were untreated (basal) or treated with $0.1 \mathrm{nM}$ insulin or IGF-1 in culture medium (RPMI-1640) for $24 \mathrm{~h}$ at $37^{\circ} \mathrm{C}$. Basal intracellular $\mathrm{Ca}^{2+}$ levels $\left(\mathrm{Ca}^{2+}{ }_{\mathrm{i}}\right)$ levels were recorded in cells loaded with Fura-2/AM, without (a) or upon adding CCCP plus oligomycin (b) to completely depolarize the mitochondria in order to assess mitochondrial $\mathrm{Ca}^{2+}$ retention. $\mathrm{Ca}^{2+}{ }_{\mathrm{i}}$ were also recorded in untreated (c, d) or insulin/IGF1-treated (e, f) lymphoblasts following stimulation with $1 \mathrm{mM}$ $\mathrm{H}_{2} \mathrm{O}_{2}$, in the absence (as in c) or presence (as in $\mathbf{d}$ ) of CCCP plus oligomycin. Data are the mean \pm SEM of four independent experiments, performed in triplicates or quadruplicates. Statistical analysis: ${ }^{\mathrm{t}} P<0.05$, ${ }^{\text {tt }} P<0.05$ vs untreated CTR (Student's $t$ test); ${ }^{*} P<0.01$, $* * * P<0.001$ vs respective CTR; ${ }^{\# \# \# ~} P<0.001$ vs untreated HD lymphoblasts (two-way ANOVA, followed by Bonferroni post hoc test) a.

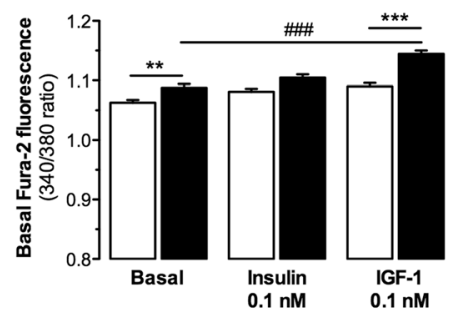

c.

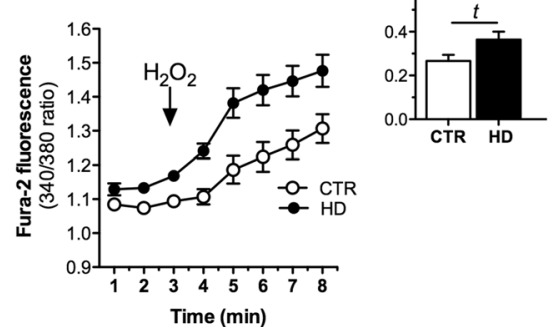

e.

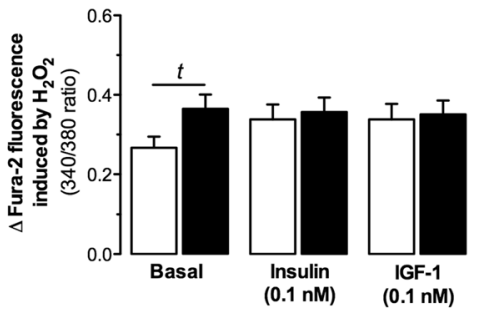

b.

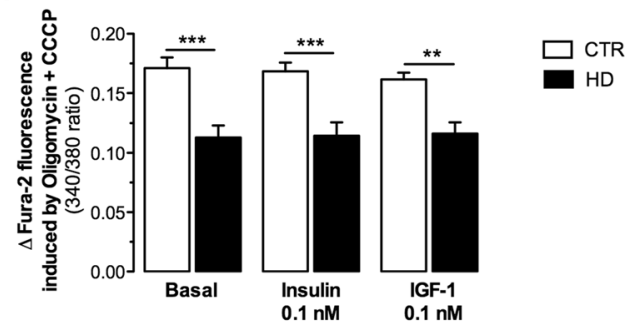

d.
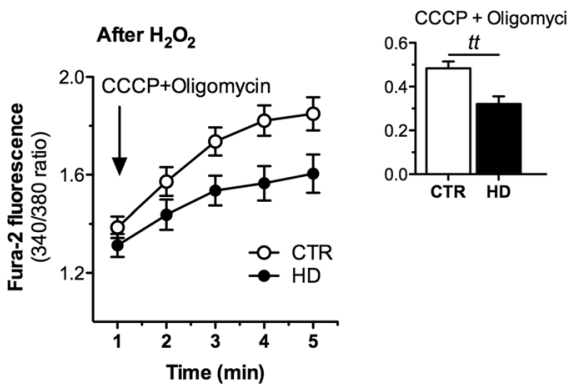

f.

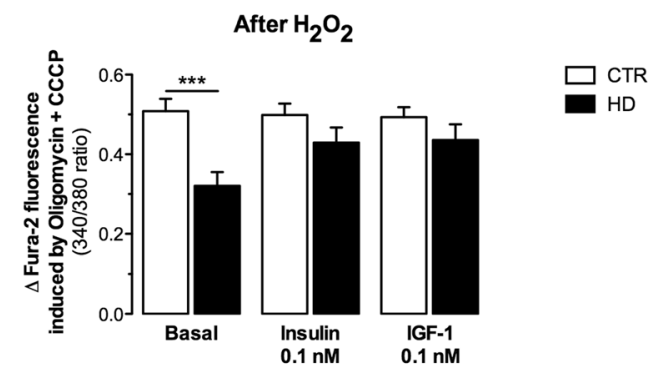

neither insulin nor IGF-1 augmented the mitochondrial capacity to accumulate $\mathrm{Ca}^{2+}$.

We further analyzed the effect of adding $\mathrm{H}_{2} \mathrm{O}_{2}(1 \mathrm{mM})$ on $\mathrm{Ca}^{2+}{ }_{\mathrm{i}}$ levels. HD lymphoblasts exhibited an increase $\mathrm{Ca}^{2+}{ }_{\mathrm{i}}$ upon incubation with $\mathrm{H}_{2} \mathrm{O}_{2}$, as compared to $\mathrm{H}_{2} \mathrm{O}_{2}$-treated CTR lymphoblasts (Fig. 8c). In the presence of insulin or IGF-1, there were no significant changes between HD and CTR cells (Fig. 8e). Moreover, $\mathrm{H}_{2} \mathrm{O}_{2}$-treated $\mathrm{HD}$ cells still showed decreased mitochondrial $\mathrm{Ca}^{2+}$ retention, examined after complete mitochondrial depolarization (Fig. 8d). This abnormal buffering capacity was partially but significantly restored following pre-exposure to both insulin and IGF-1 in $\mathrm{H}_{2} \mathrm{O}_{2}$-treated HD lymphoblasts (Fig. 8f), suggesting protection by IGF-1 under conditions of oxidative stress.

\section{Discussion}

Recent evidences suggest that impaired metabolism plays an important role in the pathogenesis of HD-affected individuals, in both central and peripheral tissues $[1,8,51]$, and the ability of insulin and IGF-1 to promote cell survival has been increasingly proven [22-24,52] including in the context of HD $[21,30]$. However, the neuroprotective role achieved by insulin and IGF-1 has been questioned. Indeed, some studies showed that high levels of IGF-1 could increase mitochondrial and oxidative stress in HD mice [35] and cognitive decline in HD patients [33, 34]. Despite these observations, in the present work, we show that activation of IGF-1/insulin signaling pathway can rescue mitochondrial function and energy production in HD peripheral blood cells. In particular, we describe that IGF-1 ameliorates mitochondrial function (evidenced through increased $\mathrm{O}_{2}$ consumption and $\Delta \psi_{\mathrm{m}}$ ) in human HD lymphoblasts derived from HD patients, namely, through phosphorylation of Htt at Ser421 and increased levels of cytochrome c.

In previous studies, we showed that insulin, at micromolar concentrations, was able to activate both IR and IGF-1R in cortical neurons by stimulation of Tyr kinase activity [24]. In the present study, IGF-1 (at low nM) completely recovered IR,IGF-1R activation in HD lymphoblasts to levels observed in CTR cells, whereas insulin was less efficient when compared to IGF-1. Decreased IR,IGF-1R phosphorylation, due to the expression of $\mathrm{mHtt}$, has been linked to decreased activation of ERK and Akt downstream signaling pathways, as observed in HD patients and mouse models expressing $\mathrm{mHtt}$ $[21,43,53]$. Concordantly, increased IGF-1 and IGF-1R expression was recently associated to enhanced ERK and 
Akt phosphorylation [28]. The present work demonstrates that exposure to IGF-1 recovered Akt activation and increased $\mathrm{P}($ Ser421)Htt levels; this is in accordance with our previous and more recent studies showing that neuroprotective effects mediated by IGF-1 require phosphorylation of Htt at Ser421 exerted by Akt, thus increasing neuronal survival and improving motor performance in HD YAC128 mice [21, 30]. Indeed, several phosphorylated sites have been identified on Htt protein; most of them were reported to be protective. Accordingly, phosphorylation at Ser241 by Akt restores $\mathrm{Htt}$ function in anterograde and retrograde axonal transport [54] and reduces the nuclear accumulation and cleavage of Htt [55]. Moreover, enhanced $\mathrm{P}(\mathrm{S} 421) \mathrm{Htt}$ provided neuroprotection from $N$-methyl-D-aspartate-mediated excitotoxicity in YAC128 mouse model [56]. These evidences could be explained since serine residues phosphorylation in $\mathrm{Htt} \mathrm{N}$-terminal can suppress $\mathrm{Htt}$ accumulation by altering protein aggregation properties, thereby reducing toxicity [57-59].

Increased ERK phosphorylation was also shown to provide a pro-survival effect, a result already demonstrated before [28]. Surprisingly, the present work demonstrates that mTor activation, known to be involved in macroautophagy inhibition [60], appears to be increased in HD lymphoblasts when compared to CTR cells, despite presenting decreased total protein levels, which suggests a downregulation of autophagic mechanisms in HD cells. Indeed, increased levels of $\mathrm{Ca}^{2+}{ }_{i}$ under basal conditions in HD lymphoblasts were previously reported to trigger mTor complex [61]. Moreover, apart from Akt, S6 kinase 1, a serine/threonine kinase directly activated by the ERK pathway, may be responsible for mTor activation $[62,63]$.

Previous studies performed by Seong et al. [64] demonstrated decreased ATP levels in lymphoblastoid cell lines obtained from homozygous HD patients, with 41-50 CAG repeats. Accordingly, our data also show decreased ATP levels in HD lymphoblasts, which were restored by IGF-1 and insulin. Other studies in muscle from HD patients and $\mathrm{mHtt}-$ transfected HeLa cells also showed a significant reduction in both ATP [65] and phosphocreatine [66] levels. In the present work, treatment of HD lymphoblasts with insulin or IGF-1 (at low $\mathrm{nM}$ ) restored phosphocreatine levels, indicating that activation of insulin/IGF-1 signaling pathways can rescue energy levels in human blood cells expressing mHtt. Previously, we observed that insulin (at $\mu \mathrm{M}$ range) completely prevented the decrease in intracellular ATP levels evoked by oxidative stress in primary cortical neurons [23].

Besides energetic defects, mitochondrial deregulation plays an important role in HD pathogenesis [7, 9, 18]. In fact, expression of $\mathrm{mHtt}$ caused loss of mitochondrial function [67] and altered mitochondrial morphogenesis with increased mitochondrial fission and reduced fusion [7]. In the present work, impaired mitochondrial function in HD lymphoblasts was confirmed by decreased $\mathrm{O}_{2}$ consumption and reduced
$\Delta \psi_{\mathrm{m}}$, as well as increased lactate levels, which may account for by a compensatory glycolytic response [68], as previously reported in the striatum and occipital cortex of HD patients $[15,69]$. Similar increased glycolytic metabolism linked to moderate mitochondrial dysfunction was recently described by us in HD cybrid lines [19]. Although some studies advocated increased oxygen consumption, while others showed no alterations [70, 71], striatal STHdh ${ }^{\mathrm{Q} 111}$ cell lines evidenced decreased $\mathrm{O}_{2}$ consumption and ATP production [72]. In accordance, studies in yeast expressing a 103Q-Htt exhibited a significant decrease in $\mathrm{O}_{2}$ consumption associated with dysfunctional mitochondrial respiratory chain complexes II and III activities [73]. Recently, we also showed reduced activity of complex I in human platelets derived from presymptomatic and symptomatic HD carriers, evidencing mitochondrial changes before the onset of HD clinical symptoms [12]. Unlike these evidences, HD lymphoblasts [11] and cybrids [18] showed no changes in the activity of mitochondrial complexes I-IV or in the protein levels of complex subunits [74]. Indeed, our study also shows unchanged mitochondrial complexes activity and unaltered levels of the mitochondrial respiratory chain subunit proteins; despite this, we observed decreased levels of cytochrome $\mathrm{c}$ in HD lymphoblast's mitochondria. This observation and the fact that this protein uses the heme group as a redox intermediate for the electron transfer between complexes III and IV [75] may explain decreased $\mathrm{O}_{2}$ consumption without changes in mitochondrial complexes expression and activity in HD lymphoblasts. Accordingly, cytochrome c mouse fibroblasts mutants were not able to assemble or stabilize cytochrome c oxidase (complex IV), causing respiratory deficits in the cell [76]. The loss of $\Delta \psi_{\mathrm{m}}$ in HD lymphoblasts, observed in our study, could be related to disrupted proton translocation, as a consequence of decreased cytochrome $\mathrm{c}$, due to the an interaction of $\mathrm{mHtt}$ with the outer mitochondrial membrane [17, 67]. Moreover, decreased Tfam levels can also contribute for this dysfunction; apart from being a relevant mitochondrial transcriptional factor, Tfam has multiple roles in the maintenance of mtDNA [77]. Indeed, we previously confirmed the presence of different patterns of mtDNA variations in human HD cybrids, despite the lack of differences in mitochondrial complexes activities [18].

Importantly, the role of phosphorylated $\mathrm{Htt}$ at Ser421, previously described to be triggered by the IGF-1/Akt pathway [21], was further demonstrated to rescue mitochondrial function in lymphoblasts expressing constitutively phosphorylated Htt with 68 polyQ (480-68-S421D); under these conditions, $\Delta \psi_{\mathrm{m}}$ was completely restored to the levels of lymphoblasts expressing 17 polyQ. This effect seems to be specific since inhibition of Htt phosphorylation, following expression of 480-68-S421A, precluded $\Delta \psi_{\mathrm{m}}$ recovering. Indeed, we previously showed that activation of IGF-1/Akt pathway was able to inhibit neuronal death induced by $\mathrm{mHtt}$ 
[21] and ameliorated brain energy metabolism in YAC128 mice [30]. The present work further suggests that neuroprotection achieved by insulin and IGF-1 may be due to an improvement of mitochondrial function and consequent rectified cellular energy levels. Of relevance, decreased cytochrome c levels were largely recovered by IGF-1 only, supporting increased mitochondrial function through normalization of $\mathrm{O}_{2}$ consumption and $\Delta \psi_{\mathrm{m}}$.

Bioenergetics is not the only role played by mitochondria, as the organelle is also a key mediator of apoptosis and can be linked, directly and/or indirectly, to many common deleterious processes involved in neurodegeneration. Previous studies in neuronal cells expressing $\mathrm{N}$-terminal $\mathrm{mHtt}$ revealed activation of caspase- 3 with no significant release of apoptotic proteins, namely, cytochrome $\mathrm{c}$ and AIF into the cytosol [78]. However,
HD cybrids showed increased cytochrome $\mathrm{c}$ and AIF release from mitochondria, associated with the translocation of proapoptotic protein Bax to mitochondria [18]. Bax overexpression was also shown to be present in B lymphocytes obtained from human patients and associated with decreased $\Delta \psi_{\mathrm{m}}[9]$. Furthermore, we showed recently the release of cytochrome $c$ and AIF and caspase- 3 activation in HD knock-in striatal cells [79]. Nevertheless, human HD lymphoblasts used in the present study did not exhibit activation of intrinsic apoptotic pathway under basal conditions. However, calcium homeostasis appears to be deregulated in these cells; in fact, decreased $\Delta \psi_{\mathrm{m}}$ and increased susceptibility to $\mathrm{Ca}^{2+}$ loads are other consequences of mitochondrial dysfunction, directly correlated with CAG repeat expansion, as shown previously $[80,81]$. In the present study, impaired calcium homeostasis in $\mathrm{HD}$ human cells was evidenced through $\mathrm{Ca}^{2+}{ }_{\mathrm{i}}$ rise under basal

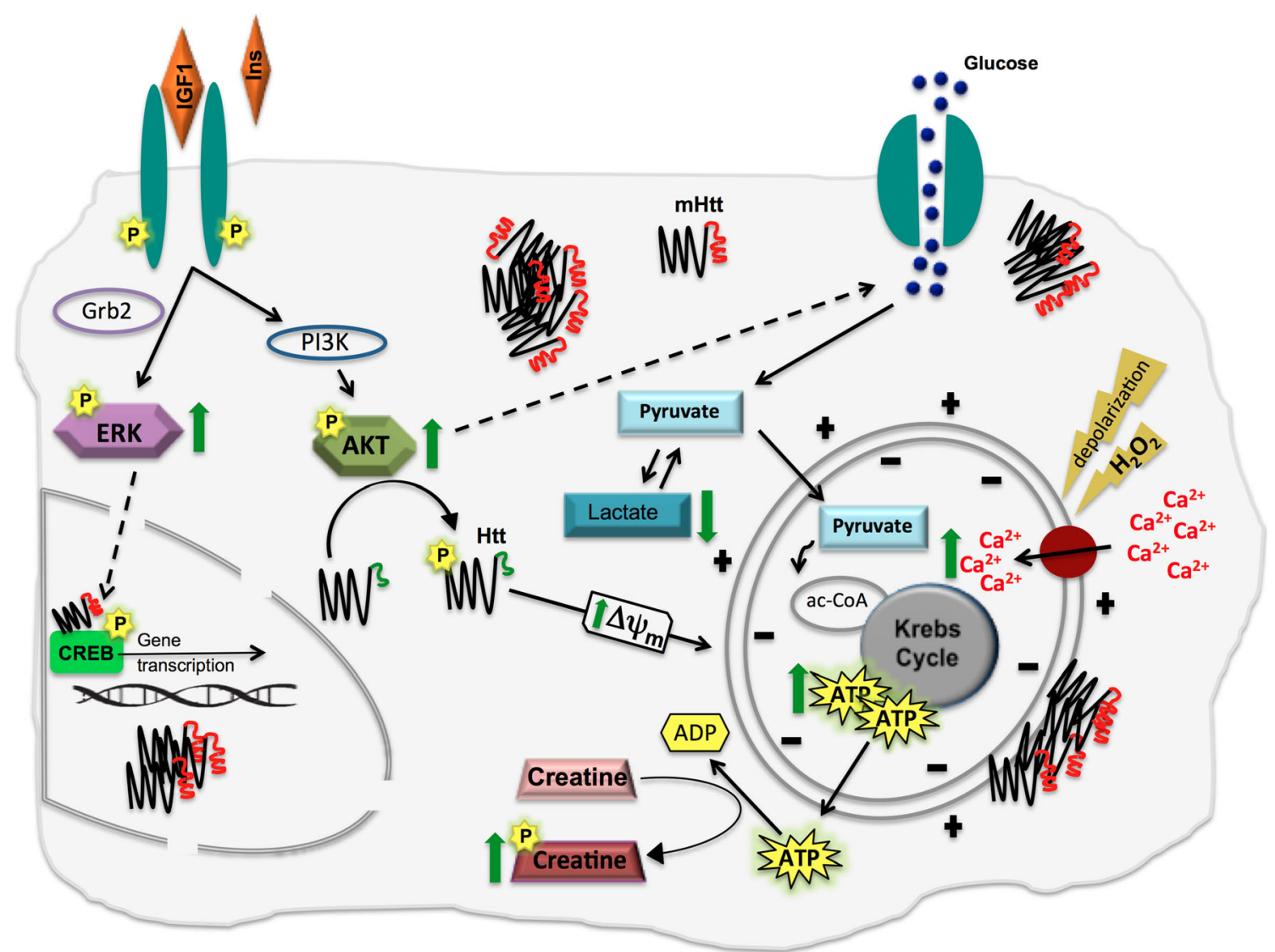

Fig. 9 IGF-1/Akt/P-Htt signaling pathway promotes protection against $\mathrm{mHtt}-$ mediated mitochondrial and metabolic dysfunction in HD lymphoblasts. Treatment with insulin or IGF-1 lead to multiple changes (represented in green arrows) through the phosphorylation of IR and/or IGF$1 \mathrm{R}$, further leading to the activation of PI-3K/Akt and ERK signaling pathways. Active Akt directly phosphorylates Htt at Ser421, which in turn can rescue the $\Delta \psi_{\mathrm{m}}$ in HD lymphoblasts. Moreover, activated ERK can translocate to the nucleus and phosphorylate transcription factors (such as CREB, among others), which in turn can bind promoters of many genes important in promoting growth and preventing apoptosis (e.g., [84]). Under oxidative stress (evoked by $\left.\mathrm{H}_{2} \mathrm{O}_{2}\right), \mathrm{Ca}^{2+}{ }_{\mathrm{i}}$ levels are increased, along with decreased mitochondrial $\mathrm{Ca}^{2+}$ accumulation, being the later recovered by IGF-1 and insulin. At metabolic level, insulin and particularly IGF-1 are able to rescue cellular energy status by increasing ATP and phosphocreatine levels and decreasing lactate levels. PI-3K Phosphatidylinositide 3-kinase, Grb2 growth factor receptor-bound protein, Akt protein kinase B, ERK extracellular signal regulated kinase, $\mathrm{Htt}$ huntingtin, $m H t t$ mutant huntingtin, $\Delta \psi_{m}$ mitochondrial membrane potential, $C R E B$ cAMP response element-binding protein, $\mathrm{H}_{2} \mathrm{O}_{2}$ hydrogen peroxide, $a c-C o A$ acetyl-coenzyme A, $P$ phosphorylation, Ins insulin, $I G F 1$ insulin growth factor 1 
conditions and following exposure to $\mathrm{H}_{2} \mathrm{O}_{2}$, suggesting a deficiency in the mechanisms that underlie the regulation of $\mathrm{Ca}^{2+}$, in agreement with previous publications [67, 72]. Accordingly, HD lymphoblasts mitochondria also exhibited reduced capacity to take up $\mathrm{Ca}^{2+}$, as observed following decreased release of $\mathrm{Ca}^{2+}$ into the cytosol of HD lymphoblasts after complete mitochondrial depolarization. Our results also evidenced that IGF-1 increased basal $\mathrm{Ca}^{2+}{ }_{\mathrm{i}}$ levels. Indeed, IGF-1 was previously shown to induce an increase in cytosolic $\mathrm{Ca}^{2+}$ mediated by phospholipase $\mathrm{C}$ gamma (PLCy)/inositol 1,4,5-triphosphate $\left(\mathrm{IP}_{3}\right)$-dependent signaling pathways in peripheral cells $[82,83]$, which may justify the observed increase in intracellular $\mathrm{Ca}^{2+}$ in $\mathrm{HD}$ lymphoblasts. Interestingly, in $\mathrm{H}_{2} \mathrm{O}_{2}$ pre-treated HD cells, IGF-1 and insulin improved mitochondrial $\mathrm{Ca}^{2+}$ uptake capacity, again pointing out the protective function of these peptides under oxidative stress conditions. Data suggest that increased Htt phosphorylation evoked by IGF-1/insulin may exert a protective role in stress-induced mitochondrial $\mathrm{Ca}^{2+}$ defects. In addition, in our lab, insulin and IGF-1 (also at low $\mathrm{nM}$ ) improved mitochondrial function and reduced mitochondrial-driven reactive oxygen species caused by $\mathrm{mHtt}$ in HD knock-in striatal cells (Ribeiro and co-authors, unpublished data).

Altogether, our findings present strong evidence that $\mathrm{mHtt}-$ mediated disruption of insulin/IGF-1 downstream pathways, including Htt phosphorylation at Ser421, can lead to mitochondrial and metabolic dysfunction in HD human peripheral blood cells, namely, lymphoblastoid cell lines. Exposure to IGF-1 (in particular) and insulin play an important role in rescuing features of mitochondrial abnormalities and energy deficits, namely, by increasing $\Delta \psi_{\mathrm{m}}$, cytochrome c protein levels and restoring mitochondrial $\mathrm{Ca}^{2+}$ uptake capacity upon an oxidant stress stimulus (Fig. 9). More specifically, we demonstrate that IGF-1 enhances mitochondrial function in human HD peripheral cells through increased activation of intracellular signaling pathways and $\mathrm{Htt}$ phosphorylation at Ser421.

\begin{abstract}
Acknowledgments We wish to thank Doctor Luísa Cortes, head of Microscope Imaging Center of Coimbra (MICC) of CNC for the confocal image acquisition and analysis. This work was supported by "Fundação para a Ciência e Tecnologia" (FCT), Portugal, grants reference PTDC/SAU-FCF/66421/2006 and PTDC/SAU-FCF/108056/2008, and co-financed by COMPETE-"Programa Operacional Factores de Competitividade," QREN, and the European Union (FEDER-"Fundo Europeu de Desenvolvimento Regional"). CNC is supported by project PEst-C/SAU/LA0001/2013-2014. L. Naia, M. Ribeiro, and M.J. Ribeiro are supported by Ph.D. fellowships from FCT (SFRH/BD/86655/2012, SFRH/BD/88983/2012, and SFRH/BD/41285/899/2007, respectively). T. Cunha-Oliveira, A.I. Duarte, T.R. Rosenstock, and M.N. Laço are supported by postdoctoral fellowships from FCT (SFRH/BPD/34711/ 2007, SFRH/BPD/26872/2006, SFRH/BPD/44246/2008, and SFRH/BPD/91811/2012, respectively).
\end{abstract}

Conflicts of Interest Statement The authors declare that they have no conflicts of interest.

\section{References}

1. Gil JM, Rego AC (2008) Mechanisms of neurodegeneration in Huntington's disease. Eur J Neurosci 27:2803-2820

2. Zuccato C, Valenza M, Cattaneo E (2009) Molecular mechanisms and potential therapeutical targets in Huntington's disease. Physiol Rev 90:905-981

3. MacDonald ME, Gines S, Gusella JF, Wheeler VC (2003) Huntington's disease. NeuroMolecular Med 4:7-20

4. Vonsattel JP, DiFiglia M (1998) Huntington disease. J Neuropathol Exp Neurol 57:369-384

5. Cattaneo E, Rigamonti D, Goffredo D, Zuccato C, Squitieri F, Sipione S (2001) Loss of normal huntingtin function: new developments in Huntington's disease research. Trends Neurosci 24:182-188

6. Ribeiro M, Rosenstock TR, Cunha-Oliveira T, Ferreira IL, Oliveira CR, Rego AC (2012) Glutatione redox cycle dysregulation in Huntington's disease knock-in striatal cells. Free Radic Biol Med 53:1857-1867

7. Kim J, Moody JP, Edgerly CK, Bordiuk OL, Cormier K, Smith K, Beal MF, Ferrante RJ (2010) Mitochondrial loss, dysfunction and altered dynamics in Huntington's disease. Hum Mol Genet 19:39193935

8. Rosenstock TR, Duarte AI, Rego AC (2010) MitochondrialAssociated Metabolic Changes and Neurodegeneration in Huntington's disease - from Clinical Features to the Bench. Curr Drug Targets 11:1-16

9. Almeida S, Sarmento-Ribeiro AB, Januário C, Rego AC, Oliveira CR (2008) Evidence of apoptosis and mitochondrial abnormalities in peripheral blood cells of Huntington's disease patients. Biochem Biophys Res Commun 374:599-603

10. Pettegrew JW, Nichols JS, Stewart RM (1980) Membrane studies in Huntington's disease: steady-state fluorescence studies of intact erythrocytes. Ann Neurol 8:381-386

11. Sawa A, Wiegand GW, Cooper J, Margolis RL, Sharp AH, Lawler JF Jr, Greenamyre JT, Snyder SH, Ross CA (1999) Increased apoptosis of Huntington disease lymphoblasts associated with repeat length-dependent mitochondrial depolarization. Nat Med 5:1194-1198

12. Silva AC, Almeida S, Laço M, Duarte AI, Domingues J, Oliveira CR, Januário C, Rego AC (2013) Mitochondrial respiratory chain complex activity and bioenergetics alterations in human platelets derived from pre-symptomatic and symptomatic Huntington's disease carriers. Mitochondrion 13:801-809

13. Sassone J, Colciago C, Cislaghi G, Silani V, Ciammola A (2009) Huntington's disease: the current state of research with peripheral tissues. Exp Neurol 219:385-397

14. Gu M, Gash MT, Mann VM, Javoy-Agid F, Cooper JM, Schapira AH (1996) Mitochondrial defect in Huntington's disease caudate nucleus. Ann Neurol 39:385-389

15. Jenkins BG, Koroshetz WJ, Beal MF, Rosen BR (1993) Evidence for impairment of energy metabolism in vivo in Huntington's disease using localized 1H NMR spectroscopy. Neurology 43:2689-2695

16. Lodi R, Schapira AH, Manners D, Styles P, Wood NW, Taylor DJ, Warner TT (2000) Abnormal in vivo skeletal muscle energy metabolism in Huntington's disease and dentatorubropallidoluysian atrophy. Ann Neurol 48:72-76

17. Song W, Chen J, Petrilli A et al (2011) Mutant huntingtin binds the mitochondrial fission GTPase dynamin-related protein-1 and increases its enzymatic activity. Nat Med 17:377-382

18. Ferreira IL, Nascimento MV, Ribeiro M, Almeida S, Cardoso SM, Grazina M, Pratas J, Santos MJ, Januário C, Oliveira CR, Rego AC (2010) Mitochondrial-dependent apoptosis in Huntington's disease human cybrids. Exp Neurol 222:243-255

19. Ferreira IL, Cunha-Oliveira T, Nascimento MV, Ribeiro M, Proença MT, Januário C, Oliveira CR, Rego AC (2011) Bioenergetics 
dysfunction in Huntington's disease human cybrids. Exp Neurol 231: $127-134$

20. Cole GM, Frautschy SA (2007) The role of insulin and neurotrophic factor signaling in brain aging and Alzheimer's disease. Exp Gerontol 42:10-21

21. Humbert S, Bryson EA, Cordelieres FP, Connors NC, Datta SR, Finkbeiner S, Greenberg ME, Saudou F (2002) The IGF-1/Akt pathway is neuroprotective in Huntington's disease and involves Huntingtin phosphorylation by Akt. Dev Cell 2:831-837

22. Duarte AI, Santos MS, Oliveira CR, Rego AC (2005) Insulin neuroprotection against oxidative stress in cortical neurons - involvement of uric acid and glutathione antioxidant defences. Free Radic Biol Med 39:876-889

23. Duarte AI, Proenca T, Oliveira CR, Santos MS, Rego AC (2006) Insulin restores metabolic function in cultured cortical neurons subjected to oxidative stress. Diabetes 55:2863-2870

24. Duarte AI, Santos P, Oliveira CR, Santos MS, Rego AC (2008) Insulin neuroprotection against oxidative stress is mediated by Akt and GSK- $3 \beta$ signaling pathways and changes in protein expression. Biochim Biophys Acta 1783:994-1002

25. Zheng WH, Kar S, Quirion R (2002) Insulin-like growth factor-1induced phosphorylation of transcription factor FKHRL1 is mediated by phosphatidylinositol 3-kinase/Akt kinase and role of this pathway in insulin-like growth factor-1-induced survival of cultured hippocampal neurons. Mol Pharmacol 62:225-233

26. Aberg MA, Aberg ND, Hedbäcker H, Oscarsson J, Eriksson PS (2000) Peripheral infusion of IGF-I selectively induces neurogenesis in the adult rat hippocampus. J Neurosci 20:2896-2903

27. Trejo JL, Carro E, Torres-Aleman I (2001) Circulating insulinlike growth factor I mediates exercise-induced increases in the number of new neurons in the adult hippocampus. J Neurosci 21:1628-1634

28. Sasone L, Reali V, Pellegrini L, Villanova L, Aventaggiato M, Marfe G, Rosa R, Nebbioso M, Tafani M, Fini M, Russo MA, Pucci B (2013) SIRT1 silencing confers neuroprotection through IGF-1 pathway activation. J Cell Physiol 228:1754-1761

29. Chang HC, Yang YR, Wang PS, Kuo CH, Wang RY (2013) The neuroprotective effects of intramuscular insulin-like growth factor-I treatment in brain ischemic rats. PLoS One 8:e64015

30. Lopes C, Ribeiro M, Duarte AI, Humbert S, Saudou F, Pereira de Almeida L, Hayden M, Rego AC (2014) IGF-1 intranasal administration rescues Huntington's disease phenotypes in YAC128 mice. Mol Neurobiol 49:1126-1142

31. Pouladi MA, Xie Y, Skotte NH et al (2010) Full-length huntingtin levels modulate body weight by influencing insulin-like growth factor 1 expression. Hum Mol Genet 19:1528-1538

32. Dalrymple A, Wild EJ, Joubert R et al (2007) Proteomic profiling of plasma in Huntington's disease reveals neuroinflammatory activation and biomarker candidates. J Proteome Res 6:28332840

33. Saleh N, Moutereau S, Durr A, Krystkowiak P, Azulay JP, Tranchant C, Broussolle E, Morin F, Bachoud-Lévi AC, Maison P (2009) Neuroendocrine disturbances in Huntington's disease. PLoS One 4: e4962

34. Saleh N, Moutereau S, Azulay JP, Verny C, Simonin C, Tranchant C, El Hawajri N, Bachoud-Lévi AC, Maison P (2010) High insulinlike growth factor $\mathrm{I}$ is associated with cognitive decline in Huntington disease. Neurology 75:57-63

35. Sadagursky M, Cheng Z, Rozzo A, Palazzolo I, Kelley GR, Dong X, Krainc D, White MF (2011) IRS2 increases mitochondrial dysfunction and oxidative stress in a mouse model of Huntington disease. $\mathrm{J}$ Clin Invest 121:4070-4081

36. Almeida S, Domingues A, Rodrigues L, Oliveira CR, Rego AC (2004) FK506 prevents mitochondrial-dependent apoptotic cell death induced by 3-nitropropionic acid in rat primary cortical cultures. Neurobiol Dis 17:435-444
37. Stocchi V, Cucchiarini L, Magnani M, Chiarantini L, Palma P, Crescentini G (1985) Simultaneous extraction and reverse-phase high-performance liquid chromatographic determination of adenine and pyridine nucleotides in human red blood cells. Anal Biochem $146: 118-124$

38. Lamprecht W, Stein P, Heinz F, Weissner H (1974) Creatine phosphate. In: Bergmeyer H (ed) Methods of enzymatic analysis, vol 4. Academic Press, New York, pp 1777-1781

39. Ragan CI, Wilson MT, Darley-Usmar VM, Lowe PN (1967) Subfractionation of mitochondria and isolation of the proteins of oxidative phosphorylation. In: Darley-Usmar VM, Rickwood D, Wilson MT (eds) Mitochondria, a practical approach. IRL Press, London, pp 79-112

40. Hatefi Y, Stiggall DL (1978) Preparation and properties of succinate: ubiquinone oxidoreductase (complex II). Methods Enzymol 53:2127

41. Wharton DC, Tzagotoff A (1967) Cytochrome oxidase from beef heart mitochondria. Methods Enzymol 10:245-250

42. Coore HG, Denton RM, Martin BR, Randle PJ (1971) Regulation of adipose tissue pyruvate dehydrogenase by insulin and others hormones. Biochem J 125:115-127

43. Colin E, Régulier E, Perrin V, Dürr A, Brice A, Aebischer P, Deéglon N, Humbert S, Saudou F (2005) Akt is altered in an animal model of Huntington's disease and in patients. Eur J Neurosci 21:1478-1488

44. Stamper BD, Mecham B, Park SS, Wilkerson H, Farin FM, Bever RP, Bammler TK, Mangravite LM, Cunningham ML (2012) Transcriptome correlation analysis identifies two unique craniosynostosis subtypes associated with IRS1 activation. Physiol Genomics 44:1154-1163

45. Rechler MM, Zapf J, Nissley SP, Froesch ER, Moses AC, Podskalny JM, Schilling EE, Humbel RE (1980) Interactions of insulin-like growth factors I and II and multiplication-stimulating activity with receptors and serum carrier proteins. Endocrinology 107:1451-1459

46. Summers SA, Kao AW, Kohn AD, Backus GS, Roth RA, Pessin JE, BirnBaum MJ (1999) The role of glycogen synthase kinase 3beta in insulin-stimulated glucose metabolismo. J Biol Chem 274:17934 17940

47. Cole A, Frame S, Cohen P (2004) Further evidence that the tyrosine phosphorylation of glycogen synthase kinase-3 (GSK3) in mammalian cells is an autophosphorylation event. Biochem J 377:249-255

48. Macho A, Decaudin D, Castedo M, Hirsch T, Susin SA, Zamzami N, Kroemer G (1996) Chloromethyl-X-Rosamine is an aldehyde-fixable potential-sensitive fluorochrome for the detection of early apoptosis. Cytometry 25:333-340

49. Kaufman BA, Durisic N, Mativetsky JM, Costantino S, Hancock MA, Grutter P, Shoubridge EA (2007) The mitochondrial transcription factor TFAM coordinates the assembly of multiple DNA molecules into nucleoid-like structures. Mol Biol Cell 18:3225-3236

50. Wang J, Silva JP, Gustafsson CM, Rustin P, Larsson NG (2001) Increased in vivo apoptosis in cells lacking mitochondrial DNA gene expression. Proc Natl Acad Sci U S A 98:4038-4043

51. Naia L, Ribeiro MJ, Rego AC (2011) Mitochondrial and metabolicbased protective strategies in Huntington's disease: the case of creatine and coenzyme Q. Rev Neurosci 23:13-28

52. Palazzolo I, Stack C, Kong L, Musaro A, Adachi H, Katsuno M, Sobue G, Taylor JP, Sumner CJ, Fischbeck KH, Pennuto M (2009) Overexpression of IGF-1 in muscle attenuates disease in a mouse model of spinal and bulbar muscular atrophy. Neuron 63:316-328

53. Apostol BL, Illes K, Pallos J, Bodai L, Wu J, Strand A, Schweitzer ES, Olson JM, Kazantsev A, Marsh JL, Thompson LM (2006) Mutant huntingtin alters MAPK signaling pathways in PC12 and striatal cells: ERK1/2 protects against mutant huntingtin-associated toxicity. Hum Mol Genet 15:273-285

54. Zala D, Colin E, Rangone H, Liot G, Humbert S et al (2008) Phosphorylation of mutant huntingtin at $\mathrm{S} 421$ restores anterograde and retrograde transport in neurons. Hum Mol Genet 17:3837-3846 
55. Warby SC, Doty CN, Graham RK, Shively J, Singaraja RR et al (2009) Phosphorylation of huntingtin reduces the accumulation of its nuclear fragments. Mol Cell Neurosci 40:121-127

56. Metzler M, Gan L, Mazarei G, Graham RK, Liu L, Bissada N, Lu G, Leavitt BR, Hayden MR (2010) Phosphorylation of huntingtin at Ser421 in YAC128 neurons is associated with protection of YAC128 neurons from NMDA-mediated excitotoxicity and is modulated by PP1 and PP2A. J Neurosci 30:14318-14329

57. Havel LS, Wang CE, Wade B, Huang B, Li S et al (2011) Preferential accumulation of $\mathrm{N}$-terminal mutant huntingtin in the nuclei of striatal neurons is regulated by phosphorylation. Hum Mol Genet 20:1424 1437

58. Gu X, Greiner ER, Mishra R, Kodali R, Osmand A et al (2009) Serines 13 and 16 are critical determinants of full-length human mutant huntingtin induced disease pathogenesis in HD mice. Neuron 64:828-840

59. Mishra R, Hoop CL, Kodali R, Sahoo B, van der Wel PC et al (2012) Serine phosphorylation suppresses huntingtin amyloid accumulation by altering protein aggregation properties. J Mol Biol 424:1-14

60. Sarkar S, Ravikumar B, Floto RA, Rubinsztein DC (2009) Rapamycin and mTOR- independent autophagy inducers ameliorate toxicity of polyglutamine-expanded huntingtin and related proteinopathies. Cell Death Differ 16:46-56

61. Gulati P, Gaspers LD, Dann SG, Joaquin M, Nobukuni T, Natt F, Kozma SC, Thomas AP, Thomas G (2008) Amino acids activate mTOR complex 1 via $\mathrm{Ca} 2+/ \mathrm{CaM}$ signaling to hVps34. Cell Metab 7: 456-465

62. Chiang GG, Abraham RT (2005) Phosphorylation of mammalian target of rapamycin (mTOR) at Ser-2448 is mediated by p70S6 kinase. J Biol Chem 280:25485-25490

63. Holz MK, Blenis J (2005) Identification of S6 kinase 1 as a novel mammalian target of rapamycin (mTOR)-phosphorylating kinase. J Biol Chem 280:26089-26093

64. Seong IS, Ivanova E, Lee J-M, Choo YS, Fossale E, Anderson M, Gusella JF, Laramie JM, Myers RH, Lesort M, MacDonald ME (2005) HD CAG repeat implicates a dominant property of huntingtin in mitochondrial energy metabolism. Hum Mol Genet 14:2871-2880

65. Wang H, Lim PJ, Karbowski M, Monteiro MJ (2009) Effects of overexpression of Huntingtin proteins on mitochondrial integrity. Hum Mol Genet 18:737-752

66. Koroshetz WJ, Jenkins BG, Rosen BR, Beal MF (1997) Energy metabolism defects in Huntington's disease and effects of coenzyme Q10. Ann Neurol 41:160-165

67. Panov AV, Gutekunst CA, Leavitt BR, Hayden MR, Burke JR, Strittmatter WJ, Greenamyre JT (2002) Early mitochondrial calcium defects in Huntington's disease are a direct effect of polyglutamines. Nat Neurosci 5:731-736

68. Josefsen K, Nielsen SM, Campos A, Seifert T, Hasholt L, Nielsen JE, Nørremølle A, Skotte NH, Secher NH, Quistorff B (2010) Reduced gluconeogenesis and lactate clearance in Huntington's disease. Neurobiol Dis 40:656-662

69. Martin WR, Wieler M, Hanstock CC (2007) Is brain lactate increased in Huntington's disease? J Neurol Sci 263:70-74

70. van der Burg JM, Bacos K, Wood NI et al (2008) Increased metabolism in the R6/2 mouse model of Huntington's disease. Neurobiol Dis 29:41-51
71. Powers WJ, Videen TO, Markham J, McGee-Minnich L, AntenorDorsey JV, Hershey T, Perlmutter JS (2007) Selective defect of in vivo glycolysis in early Huntington's disease striatum. Proc Natl Acad Sci U S A 104:2945-2949

72. Milakovic T, Quintanilla RA, Johnson GV (2006) Mutant huntingtin expression induces mitochondrial calcium handling defects in clonal striatal cells: functional consequences. J Biol Chem 281:3478534795

73. Solans A, Zambrano A, Rodríguez M, Barrientos A (2006) Cytotoxicity of a mutant huntingtin fragment in yeast involves early alterations in mitochondrial OXPHOS complexes II and III. Hum Mol Genet 15:3063-3081

74. Benchoua A, Trioulier Y, Zala D, Gaillard MC, Lefort N, Dufour N, Saudou F, Elalouf JM, Hirsch E, Hantraye P (2006) Involvement of mitochondrial complex II defects in neuronal death produced by Nterminus fragment of mutated huntingtin. Mol Biol Cell 17:16521663

75. Ow YP, Green DR, Hao Z, Mak TW (2008) Cytochrome c: functions beyond respiration. Nat Rev Mol Cell Biol 9:532-542

76. Vempati UD, Han X, Moraes CT (2009) Lack of cytochrome c in mouse fibroblasts disrupts assembly/stability of respiratory complexes I and IV. J Biol Chem 284:4383-4391

77. Hayashi Y, Yoshida M, Yamato M et al (2008) Reverse of agedependent memory impairment and mitochondrial DNA damage in microglia by an overexpression of human mitochondrial transcription factor a in mice. J Neurosci 28:8624-8634

78. Reijonen S, Putkonen N, Nørremølle A, Lindholm D, Korhonen L (2008) Inhibition of endoplasmic reticulum stress counteracts neuronal cell death and protein aggregation caused by $\mathrm{N}$-terminal mutant huntingtin proteins. Exp Cell Res 314:950-960

79. Rosenstock TR, Brito OM, Lombradi V, Louros S, Ribeiro M, Almeida S, Ferreira IL, Oliveira CR, Rego AC (2011) FK506 ameliorates cell death features in Huntington's disease striatal cell models. Neurochem Int 59:600-609

80. Panov AV, Obertone T, Bennett-Desmelik J, Greenamyre JT (1999) $\mathrm{Ca}(2+)$-dependent permeability transition and complex I activity in lymphoblast mitochondria from normal individuals and patients with Huntington's or Alzheimer's disease. Ann N Y Acad Sci 893:365-368

81. Rockabrand E, Slepko N, Pantalone A, Nukala VN, Kazantsev A, Marsh JL, Sullivan PG, Steffan JS, Sensi SL, Thompson LM (2007) The first 17 amino acids of Huntingtin modulate its sub-cellular localization, aggregation and effects on calcium homeostasis. Hum Mol Genet 16:61-77

82. Ibarra C, Estrada M, Carrasco L, Chiong M, Liberona JL, Cardenas C, Díaz-Arava G, Jaimovich E, Lavandero S (2004) Insulin-like growth factor-1 induces an inositol 1,4,5-triphosphate-dependent increase in nuclear and cytosolic calcium in cultured rat cardiac myocytes. J Biol Chem 279:7554-7565

83. Valdés JA, Flores S, Fuentes EN, Osorio-Fuentealbe C, Jaimovich E, Molina A (2013) IGF-1 induces IP(3) dependent calcium signal involved in the regulation of myostatin gene expression mediated by NFAT during myoblast differentiation. J Cell Physiol 228:14521463

84. Steelman LS, Chappell WH, Abrams SL et al (2011) Roles of the Raf/MEK/ERK and PI3K/PTEN/Akt/mTOR pathways in controlling growth and sensitivity to therapy-implications for cancer and aging. Aging (Albany NY) 3:192-222 